\title{
Targeted gene delivery of BMPR2 attenuates pulmonary hypertension
}

\author{
A.M. Reynolds*,\#, M.D. Holmes*\#,๘, S.M. Danilov",\$ and P.N. Reynolds*,\#,
}

ABSTRACT: Pulmonary arterial hypertension (PAH) remains a fatal disease despite modern pharmacotherapy. Mutations in the gene for bone morphogenetic protein receptor type II (BMPR2) lead to reduced BMPR2 expression, which is causally linked to PAH. BMPR2 is predominantly expressed on pulmonary endothelium and has complex interactions with transforming growth factor (TGF)- $\beta$ signalling mechanisms.

Our objectives were to assess the effect on PAH of upregulating BMPR2 by targeted adenoviral BMPR2 gene delivery to the pulmonary vascular endothelium. We used two established rat models of PAH: chronic hypoxia and monocrotaline (MCT).

In both hypertensive models, those receiving BMPR2 had less right ventricular hypertrophy, less pulmonary vascular resistance, improved cardiac function and reduced vascular remodelling. In the MCT model, there was an increase in TGF- $\beta$, which was prevented by BMPR2 treatment. In vitro, TGF- $\beta 1$-induced endothelial-mesenchymal transition (EndMT) in human pulmonary microvascular endothelial cells, which was associated with reduced BMPR2 expression. EndMT was partially ameliorated by stimulating BMPR2 signalling with appropriate ligands even in the ongoing presence of TGF- $\beta 1$.

Collectively, these results indicate therapeutic potential for upregulation of the BMPR2 axis in $\mathrm{PAH}$, which may be, in part, mediated by countering the remodelling effects of TGF- $\beta$.

KEYWORDS: Endothelial-to-mesenchymal transition, gene therapy, hypoxia, monocrotaline, vascular remodelling

$\mathbf{P}$ ulmonary arterial hypertension (PAH) is a fatal disease characterised by pulmonary vascular remodelling, comprising an abnormal proliferation of vascular endothelial cells, smooth muscle hypertrophy and intimal thickening, with a consequent increase in pulmonary vascular resistance $[1,2]$. The disease causes progressive dyspnoea and right heart failure. Mutations in the gene for bone morphogenetic protein receptor type II (BMPR2) are causally linked to $\mathrm{PAH}[3,4]$. Mutations have been found to be present in $>80 \%$ of familial and $\sim 20 \%$ of "sporadic" cases of idiopathic PAH, and lead to reduced BMPR2 expression and signalling [5]. BMPR2 is a member of the transforming growth factor (TGF)- $\beta$ superfamily of receptors. There is evidence that PAH pathogenesis involves disordered TGF- $\beta$ signalling and, possibly, cross-talk between BMPR2 and TGF- $\beta$ signalling mechanisms. BMPR2 expression is predominantly seen on pulmonary vascular endothelium, although vascular smooth muscle expression is also present. Reduced BMPR2 expression is also observed in the pulmonary vasculature of patients with secondary $\mathrm{PAH}$, suggesting this pathway might also be important in the pathogenesis of a variety of common clinical situations, beyond those related to BMPR2 mutations, in which pulmonary hypertension is a feature [6]. Although advances in pharmacological treatments have led to improved outcomes for patients with $\mathrm{PAH}$ [7], recent national registry data from France and the USA continue to show an unacceptably high mortality in this disease, indicating the need for further therapeutic advances [8-10].

Various animal models have been extensively used in the study of $\mathrm{PAH}$, none more so than the chronic hypoxia and monocrotaline (MCT) rat models [11]. Recent studies in these models have demonstrated reduced BMPR2 levels and abnormal bone morphogenetic protein (BMP) signalling $[12,13]$. We previously showed that pre-treatment with $B M P R 2$ gene delivery reduced the PAH response in rats challenged with hypoxia [14] but the effects on

For editorial comments see page 235.

This article has supplementary material available from www.erj.ersjournals.com

AFFILIATIONS

*Lung Research Laboratory, Royal Adelaide Hospital,

"Hanson Institute,

"University of Adelaide, Adelaide SA, Australia.

${ }^{+}$Dept of Anesthesiology, University of Illinois at Chicago, and

${ }^{\S}$ Institute for Personalised Respiratory Medicine, University of Illinois at Chicago, Chicago, IL, USA

CORRESPONDENCE

P.N. Reynolds

Dept of Thoracic Medicine

Chest Clinic

Royal Adelaide Hospital

275 North Terrace

Adelaide

SA 5000

Australia

E-mail: paul.reynolds@

adelaide.edu.au

Received:

Dec 052010

Accepted after revision:

June 242011

First published online:

July 072011 
established PAH are not known. The mechanism by which BMPR2 leads to PAH is unclear but this signalling pathway has numerous influences on cell proliferation and differentiation. Complex cross-talk exists between BMPR2 and TGF- $\beta$ signalling pathways [15]. Notably, while BMPR2 expression is decreased in these animal models, TGF- $\beta$ expression is increased $[16,17]$.

In the current study, we sought first to determine whether the BMPR2 pathway could be exploited as a potential therapeutic target in established disease, i.e. the independent stimuli, chronic hypoxia and MCT. We utilised our previously developed adenovirus (Ad) vector lung targeting strategy whereby we link the Ad vector to a bispecific antibody conjugate that targets the virus to angiotensin-converting enzyme (ACE), a membranebound protease that is highly expressed on pulmonary endothelial cells $[18,19]$. We have shown that this approach improves pulmonary endothelial gene delivery [20, 21].

Herein, we show that delivery of BMPR2: 1) ameliorated the fall in BMPR2 expression induced by hypoxia or MCT challenge; 2) ameliorated the increase in TGF- $\beta$ expression seen in the MCT model; and 3) reduced development of pulmonary hypertension and associated vascular remodelling. In vitro, we found that that BMPR2 signalling may act by ameliorating TGF- $\beta$-induced changes in endothelial morphology and, possibly, endothelialmesenchymal transition (EndMT).

\section{METHODS}

\section{Animals and experimental design}

All animal protocols were reviewed and approved by the Animal Research Ethics Committee of the Institute of Medical and Veterinary Science (IMVS) (Royal Adelaide Hospital and The University of Adelaide, Adelaide, SA, Australia). Adult male Sprague Dawley rats (6-7 weeks of age and 250-350 g body mass) were used. The rats were housed in the IMVS animal care facility, and fed food and water ad libitum. Two models of PAH were used, hypoxia and MCT induced. For hypoxia, rats were maintained in our previously described normobaric hypoxic chamber [14] (10\% oxygen) for 3 weeks and then assigned to two treatment hypoxic groups. They were then given tail-vein injections of AdTrackLuc (irrelevant viral control) or AdBMPR2, each pre-incubated with anti-viral/antiACE bispecific antibody conjugate (Fab-9B9) [14]. Rats were then returned to the hypoxic chamber for a further 3 weeks then PAH assessed by cardiac catheterisation. For MCT, rats were assigned to three groups (two MCT groups $\left(60 \mathrm{mg} \cdot \mathrm{kg}^{-1}\right.$, subcutaneously injected) and one saline control group). 10 days after MCT, rats were injected with AdTrackLuc+Fab9B9 or AdBMPR2+Fab-9B9. After a further 8-10 days, PAH was assessed. For MCT and viral injections, the rats were briefly anaesthetised (isoflurane for $\sim 5 \mathrm{~min}$ ). Each dose of $\mathrm{Ad}$ vector $\left(1 \times 10^{10}\right.$ plaque-forming units) was complexed with $6 \mu \mathrm{g}$ Fab-9B9 for $30 \mathrm{~min}$ at room temperature prior to injection. Injections were via the lateral tail vein using $27 \mathrm{G}$ insulin syringes (Terumo, Elkton, MD, USA) with the total volume of Ad brought to $250 \mu \mathrm{L}$ with sterile PBS.

See the online supplement for information on the viral construct, bispecific conjugate, haemodynamic measurements, immunohistochemistry and immunoblotting.

\section{Cell culture}

Clonetics ${ }^{\circledR}$ lung-derived normal human pulmonary microvascular blood vessel endothelial cells (HPMVECs) (Cambrex Bio Science Inc., Walkersville, MD, USA) were cultured in EGM ${ }_{\mathbb{R}}-2$ MV (Cambrex Bio Science Inc.) supplemented with 5\% fetal calf serum, as recommended by the supplier, and used between passages 4 and 9 . All cells were grown in a $5 \% \mathrm{CO}_{2}$ atmosphere at $37^{\circ} \mathrm{C}$.

\section{Induction of EndMT}

The ability of TGF- $\beta 1$ to induce EndMT was assessed in HPMVEC monolayers. Cells were plated $\left(3 \times 10^{5}\right.$ per well; $\sim 50-60 \%$ confluence) into six-well plates and $24 \mathrm{~h}$ later, the medium was supplemented with recombinant human TGF- $\beta 1\left(5 \mathrm{ng} \cdot \mathrm{mL}^{-1}\right.$; R\&D Systems, Minneapolis, MN, USA) to induce EndMT. Cultures were maintained in a humidified $5 \% \mathrm{CO}_{2}$ incubator at $37^{\circ} \mathrm{C}$, all media changed every $48 \mathrm{~h}$ and cells were grown for 21 days. Unstimulated HPMVECs were passaged once a week at a 1:10 ratio, whereas TGF- $\beta$-treated cells were passaged twice a week at a ratio of 1:5 to retain cell viability. EndMT was assessed by loss of vascular endothelial (VE)-cadherin and gain of the mesenchymal markers fibronectin (extracellular domain A splice variant of cellular fibronectin) and S100A4. Phase-contrast microscopy pictures were taken with an Olympus CKX41 microscope equipped with an Olympus DP20 camera (Olympus, Tokyo, Japan).

\section{EndMT reversal experiments}

Following 18 days of TGF- $\beta 1$, the culture medium was replaced with fresh medium containing TGF- $\beta 1$ and recombinant human (rh)BMP-2 (333 ng.mL ${ }^{-1}$; R\&D Systems) or rhBMP-7 (325 ng. $\mathrm{mL}^{-1}$; R\&D Systems). The media was changed again at $48 \mathrm{~h}$ and the experiment was stopped $24 \mathrm{~h}$ later. Additional description of the methods used for immunofluorescence detection and immunoblot analysis of TGF- $\beta$-induced EndMT is provided in the online supplement.

\section{Statistical analysis}

Data are presented as mean \pm SEM. Between-group means comparisons were performed using a two-tailed unpaired t-test or one-way ANOVA, where appropriate. When the ANOVA Fvalue indicated a significant difference, the Student NewmanKeuls multiple comparison test was then used (SigmaStat; Systat Software Inc., Point Richmond, CA, USA). A p-value of $<0.05$ was considered statistically significant.

\section{RESULTS \\ Immunodetection of BMPR2-myc in the pulmonary vasculature}

Pulmonary targeting of Ad-mediated BMPR2-myc transgene expression in MCT-treated rats was confirmed by immunofluorescent staining of the myc tag. Rats that received AdCMVBMPR2 myc+Fab-9B9 10 days after MCT injection and were then killed 3 days after AdBMPR2 tail-vein injection demonstrated positive green staining in small pulmonary vessels and alveolar capillaries, confirming BMPR2-myc transgene expression (fig. 1a and b). These results are in accord with our previously published data using this vector and similar studies using reporter genes [20,21]. No staining was seen in sections incubated with no primary antibody (fig. 1c) or in sections stained for anti-c-myc from MCT-only injected rats (fig. 1d). No staining was seen in cardiac tissue sections. 

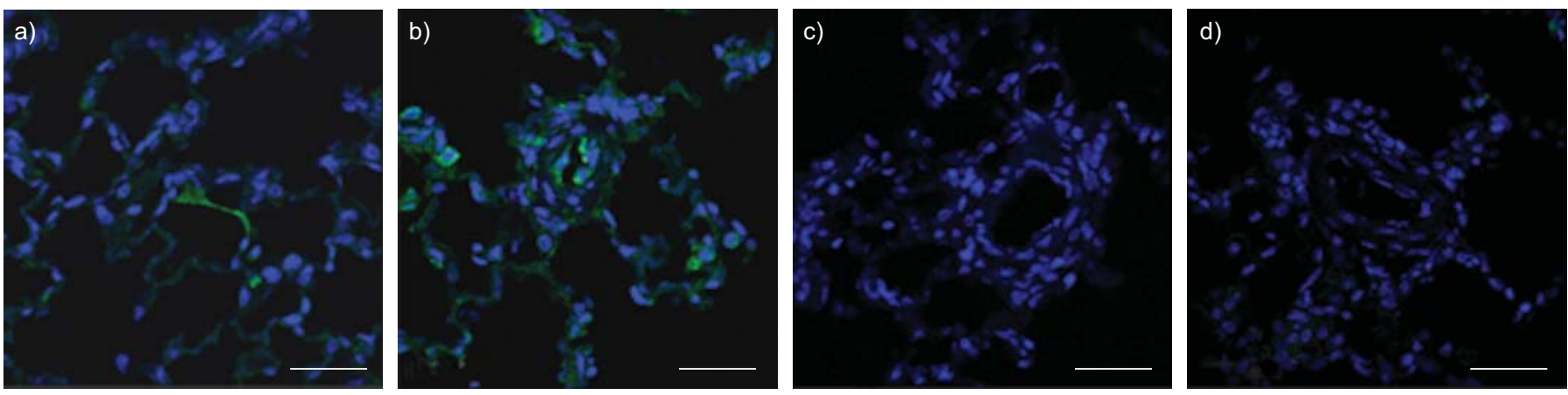
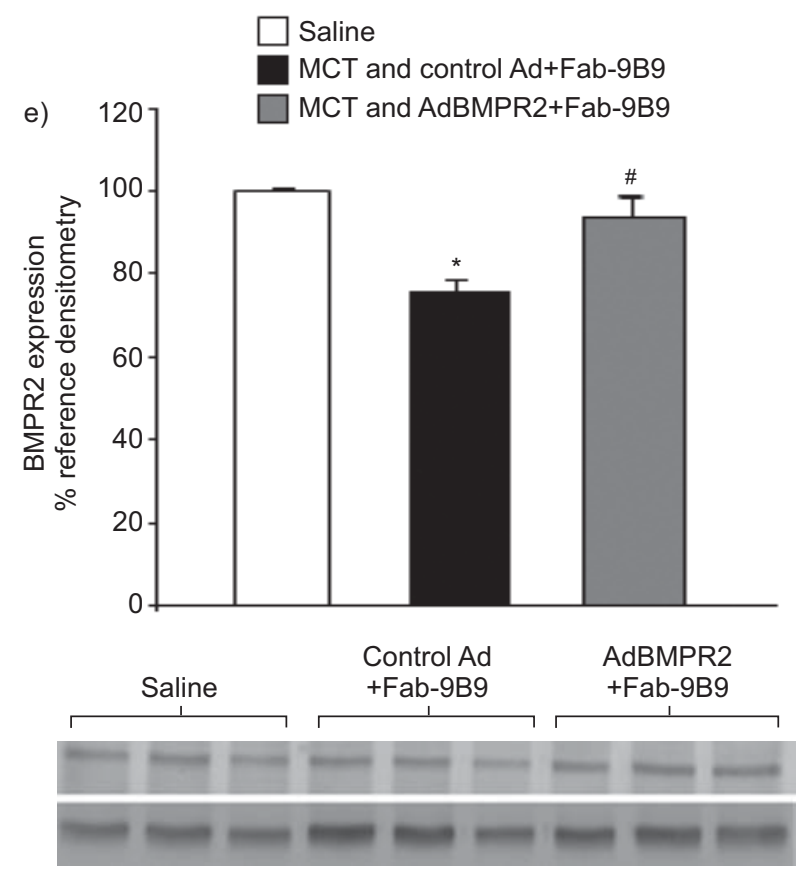
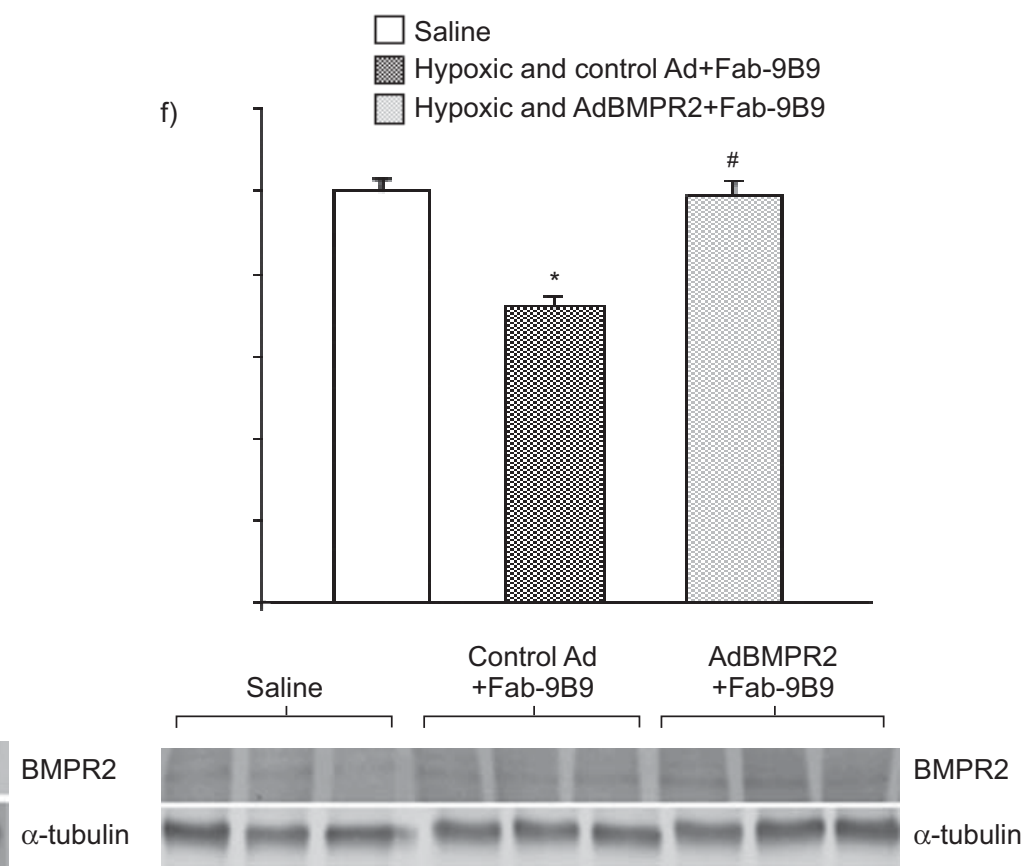

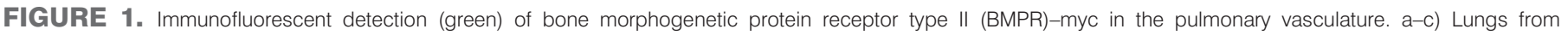

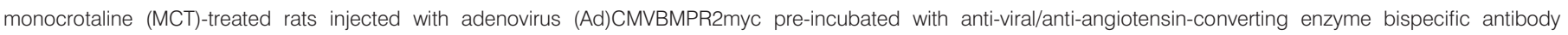

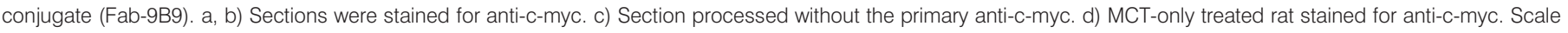

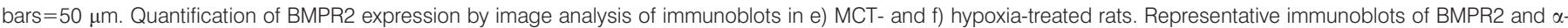

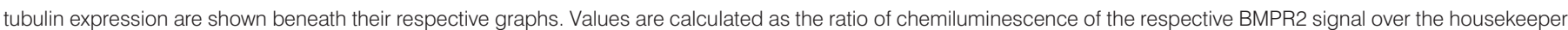

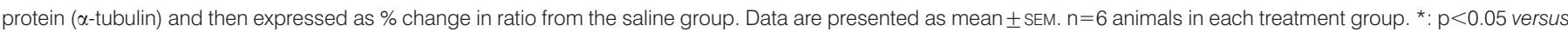
saline; ${ }^{*}: \mathrm{p}<0.05$ treatment and control Ad+Fab-9B9 versus treatment and AdBMPR2+Fab-9B9.

Compared with saline injected rats, those exposed to MCT and chronic hypoxia had significantly reduced lung BMPR2 expression, as detected by immunoblots of protein extracted from formalin-fixed, paraffin-embedded (FFPE) tissue sections (fig. $1 \mathrm{e}$ and $\mathrm{f}$, respectively) (mean $\pm \mathrm{SEM}$ BMPR2: expression saline versus $\mathrm{MCT}+$ control Ad+Fab-9B9 $100.0 \pm 1.4 \%$ versus $75.6 \pm 2.9 \% \quad(\mathrm{p}<0.05)$; saline versus chronic hypoxia+control $\mathrm{Ad}+\mathrm{Fab}-9 \mathrm{~B} 9100.0 \pm 7.8 \%$ versus $72.0 \pm 5.5 \%(\mathrm{p}<0.05))$. Of significance is that the BMPR2 Ad vector targeting strategy corrected the observed deficit in BMPR2 expression induced by MCT and hypoxia. An effect was observed 10-21 days after adenoviral $B M P R 2$ gene delivery.

\section{Effect of Ad vectors on MCT- and hypoxia-induced changes in pulmonary haemodynamics}

There was no significant difference in mean systemic arterial pressure, heart rate or body weight for the two experimental studies following anaesthesia and surgical intervention (MCT and chronic hypoxia; table 1). MCT and chronic hypoxia induced significant PAH. Right ventricular systolic pressure (RVSP) and mean pulmonary arterial pressure $\left(\bar{P}_{\text {pa }}\right)$ were significantly increased by the end-point of each study, the increases being more pronounced following MCT (fig. 2a and $\mathrm{b}$, and table 1). Both models of PAH induced a significant decrease in cardiac function as reflected by decreased cardiac output (CO) and cardiac index (CI) (fig. 2c and d, and table 1, respectively), and significant increases in pulmonary resistive indices (pulmonary vascular resistance index (PVRI) and total pulmonary vascular resistance (TPVR)) (fig. $2 \mathrm{e}$ and $\mathrm{f}$, and table 1 , respectively).

In the MCT study, compared with MCT treated rats that received an irrelevant viral control (AdTrackLuc+Fab-9B9), those receiving BMPR2 (AdBMPR2+Fab-9B9) had significantly 
TABLE 1 Haemodynamic parameters and body mass in rats for both monocrotaline (MCT) and hypoxia studies

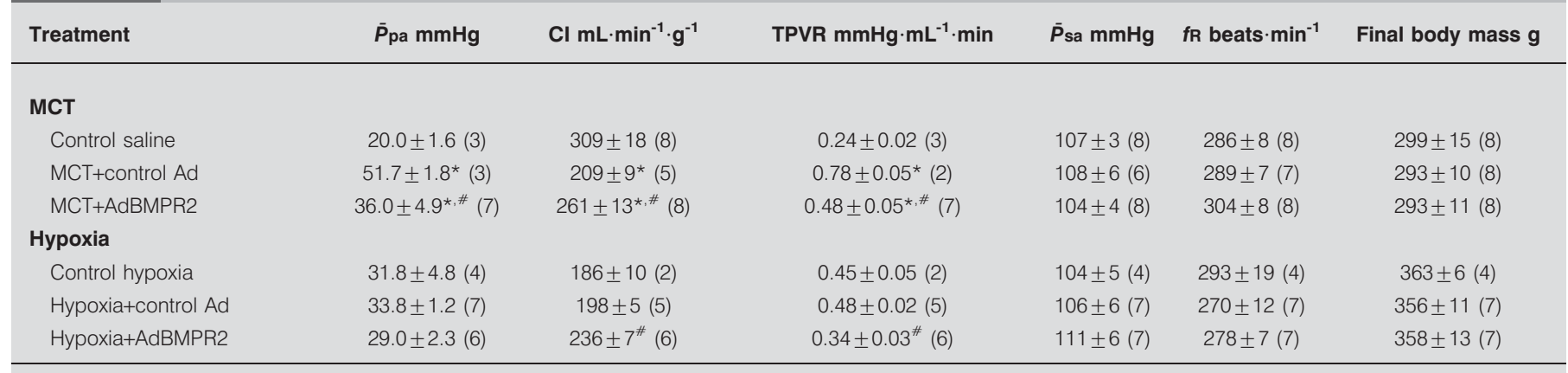

Data are presented as mean \pm SEM (n). Pिpa: mean pulmonary arterial pressure; Cl: cardiac index (cardiac output (CO)/body mass); TPVR: total pulmonary vascular resistance $\left(\bar{P}_{\mathrm{pa} / \mathrm{CO}}\right)$; $\bar{P}_{\mathrm{sa}}$ : mean systemic arterial pressure; fR: respiratory frequency; Ad: adenovirus; control Ad: AdCMVTrackLuc+Fab-9B9; AdBMPR2: AdCMVBMPR2+Fab-9B9. *: $p<0.05$ versus respective control; $*$ : $p<0.05$ treatment and control Ad+Fab-9B9 versus treatment and AdBMPR2+Fab-9B9.

decreased PAH responses (RVSP was $36 \%$ lower and $\bar{P}$ pa was $30 \%$ lower) and vascular resistance (TPVR was 38\% lower and PVRI was $48 \%$ lower), and significantly improved cardiac function (CO was $22 \%$ higher and CI was $25 \%$ higher) (fig. $2 \mathrm{a}, \mathrm{c}$ and e, and table 1). Similar findings were seen in the chronic hypoxia study, i.e. compared with hypoxic animals that received control vector, lung-targeted AdBMPR2-treated animals had significantly reduced TPVR (29\% less) and PVRI (30\% less), with a $20 \%$ improvement in both CO and CI. Although BMPR2 therapy in chronic hypoxia lowered RVSP and $\bar{P}_{\mathrm{pa}}$, the values did not reach statistical significance in this instance $(p=0.07)$ (fig. 2b, d and f, and table 1), suggesting measurement of these indices is less sensitive to change.

Severe right ventricular hypertrophy (assessed as the ratio of right ventricular (RV) free wall weight over the sum of septum (S) plus left ventricular (LV) free wall weight), was observed following $\mathrm{MCT}$ and chronic hypoxia exposure (fig. $2 \mathrm{~g}$ and $\mathrm{h}$ ). In the chronic hypoxia study, the degree of hypertrophy was not improved in control Ad+Fab-9B9-treated animals (mean \pm SEM $\mathrm{RV} /(\mathrm{LV}+\mathrm{S}$ ) $0.471 \pm 0.02)$ compared with hypoxia alone $(0.445 \pm 0.02)$. In both the MCT and hypoxia studies, $\mathrm{RV} /(\mathrm{LV}+\mathrm{S})$ was significantly reduced by targeted BMPR2 gene delivery (AdBMPR2+Fab9B9) compared with their respective control-treated rats (chronic hypoxia control Ad+Fab-9B9 versus AdBMPR2+Fab-9B9 0.471 \pm 0.020 versus $0.341 \pm 0.02(\mathrm{p}<0.05)$; MCT control $\mathrm{Ad}+\mathrm{Fab}-9 \mathrm{~B} 9$ versus AdBMPR2+Fab-9B9 $0.425 \pm 0.03$ versus $0.333 \pm 0.02(\mathrm{p}<0.05))$. No significant difference in LV (including $S$ ) was detected across all treatment groups in both the MCT and hypoxia studies. In the MCT study, LV+S in saline-, MCT control Ad+Fab-9B9- and MCT AdBMPR2 +Fab-9B9-treated rats was 0.735 $\pm 0.033,0.697 \pm$ 0.027 and $0.696 \pm 0.023 \mathrm{~g}$, respectively, while in chronic hypoxia, hypoxia control Ad+Fab-9B9 and hypoxia AdBMPR2+Fab9B9, LV+S was $0.747 \pm 0.029,0.742 \pm 0.021$ and $0.821 \pm 0.031 \mathrm{~g}$, respectively.

\section{Effect on vascular muscularisation}

Five high-power lung fields were examined in four to five rats from each treatment group, in which the number of completely muscularised vessel of $\sim 50 \mu \mathrm{m}$ diameter were counted. As shown in figure 3a, MCT induced a significant three-fold increase in the number of muscularised vessels compared with saline $(44 \pm 8$ versus $15 \pm 1.5$, respectively; $\mathrm{p}<0.005)$. Targeted BMPR2 gene delivery significantly attenuated the MCT-induced increase in vascular muscularisation by $42 \%$. Following chronic hypoxia exposure, a significant number of fully muscularised vessels was seen and the numbers were unchanged in the control Ad delivery group (hypoxia versus control Ad+Fab-9B9 $49 \pm 3.2$ versus $57 \pm 2.4$ ), whereas targeted AdBMPR2 treatment significantly decreased the number of fully muscularised vessels to $31 \pm 1.9$ $(\mathrm{p}<0.05)$ (fig. 3c). A similar effect was seen on smooth muscle area in both MCT and hypoxia experiments (fig. $3 \mathrm{~b}$ and $\mathrm{d}$, respectively). A significant $40 \%$ reduction in smooth muscle area was observed following targeted BMPR2 delivery compared with the respective control Ad+Fab-9B9 groups. Lung tissue sections representative of each treatment group and immunostained for smooth muscle $\alpha$-actin are shown in figure $3 \mathrm{e}-\mathrm{j}$.

\section{Effects on cellular proliferation}

We further assessed the sections for proliferative cell nuclear antigen (PCNA) and Ki67, and found that few proliferating cells were evident in lungs of saline-treated rats; however, 3 weeks after MCT administration, increased cell proliferation was observed in the endothelial lesions and targeted $B M P R 2$ gene delivery reduced the proliferative response (fig. $4 \mathrm{a}$ and b, respectively). In animals exposed to chronic hypoxia, increased PCNA and Ki67 staining was seen in both endothelial and smooth muscle cells; control Ad delivery did not change this proliferative response, whereas targeted BMPR2 delivery decreased PCNA- and Ki67positive endothelial (fig. $4 \mathrm{c}$ and $\mathrm{d}$, respectively) and smooth muscle (fig. 4e and f, respectively) cell numbers.

\section{Effects on lung TGF- $\beta$ expression}

Immunoblot detection of TGF- $\beta$ from FFPE sections demonstrated significantly elevated levels of TGF- $\beta$ in MCT-treated rats (mean \pm SEM $100.0 \pm 20.1 \%$ versus $172.6 \pm 26.1 \%$ of control in saline versus MCT and control Ad+Fab-9B9, respectively; fig. 5a). AdBMPR2 treatment attenuated this response $(121.7 \pm 24.3 \%)$. Consistent with this analysis, we found increased TGF- $\beta$ immunostaining in endothelial lesions of remodelled blood vessels which was less pronounced in animals that received targeted BMPR2 delivery (fig. 5b-d). In hypoxia-treated rats, differences in TGF- $\beta$ expression did not reach statistical significance $(100.0 \pm 23.4 \%$ versus $100.7 \pm 43.2 \%$ in saline versus hypoxia and control Ad+Fab-9B9, respectively, while in the 

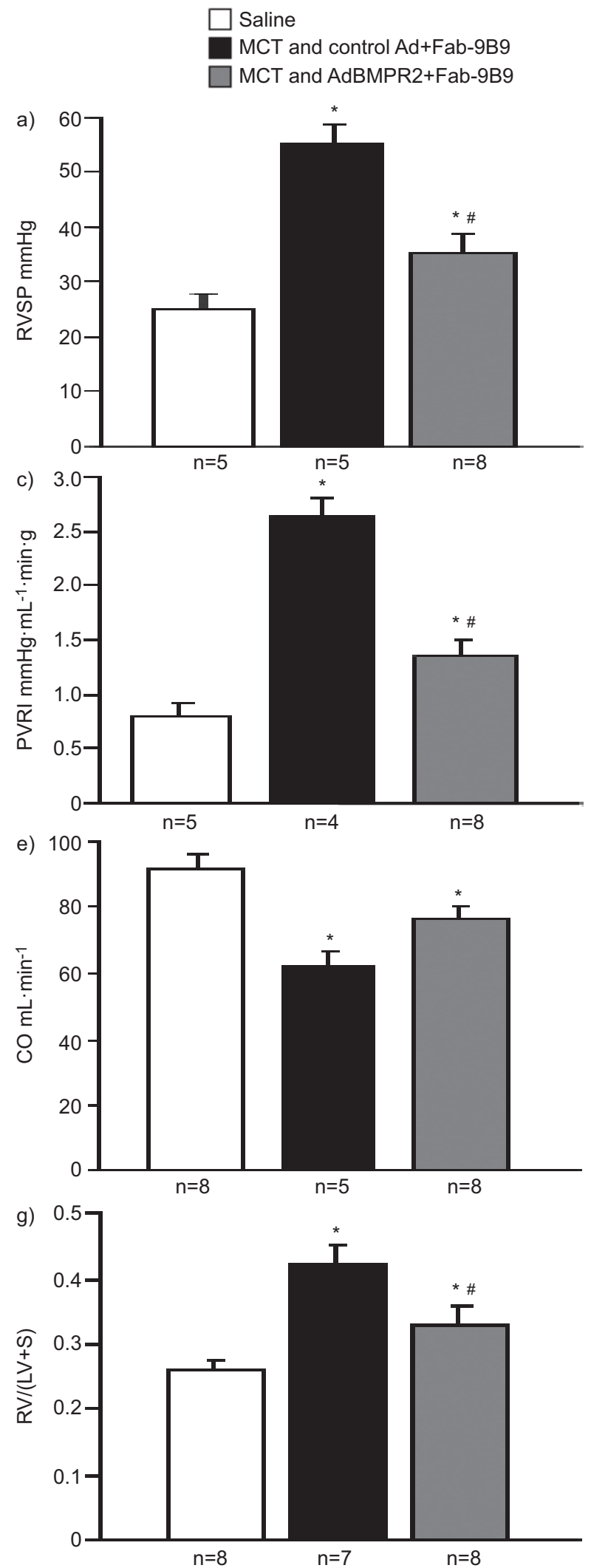

Hypoxic

Hypoxic and control Ad+Fab-9B9

Hypoxic and AdBMPR2+Fab-9B9
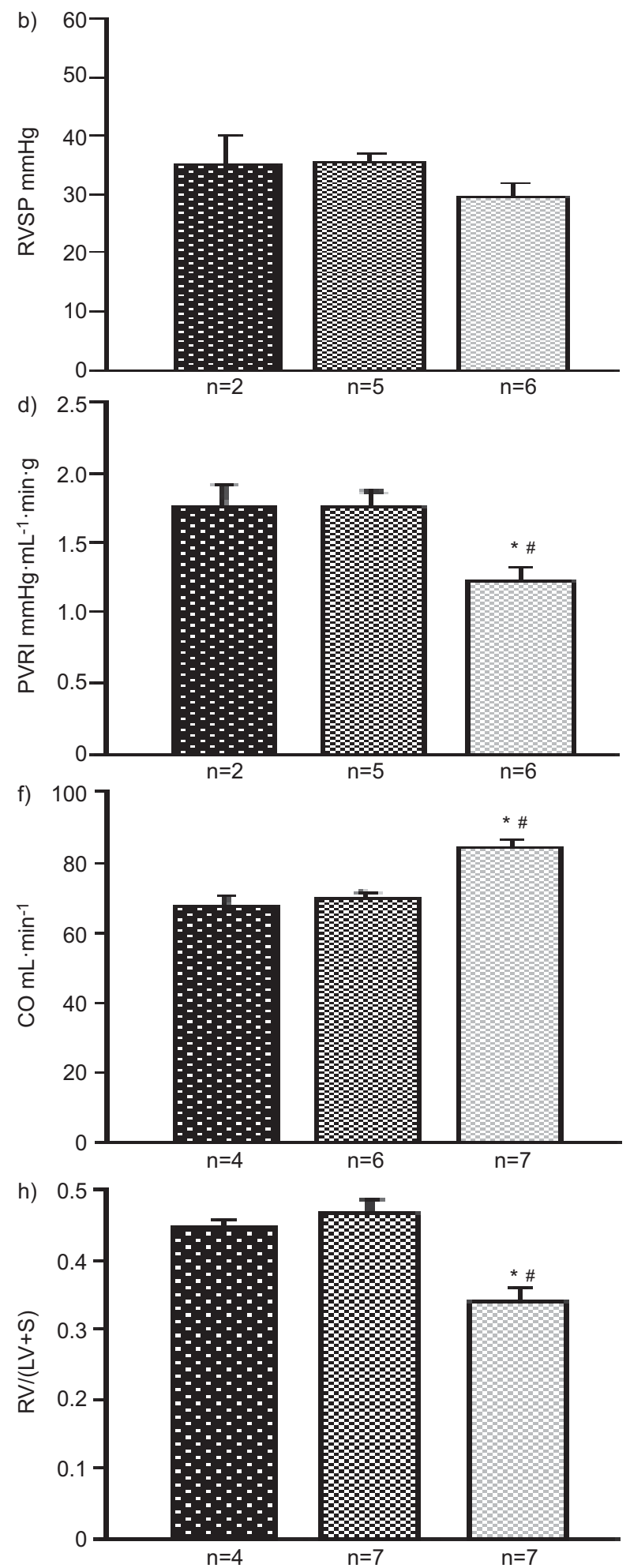

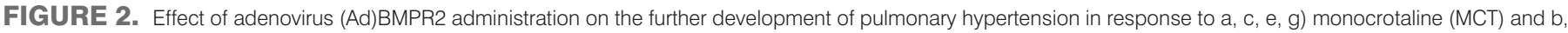
$\mathrm{d}, \mathrm{f}, \mathrm{h}$ ) chronic hypoxia. a, b) Right ventricular systolic pressures (RVSP) in a) MCT and b) hypoxia; c, d) pulmonary vascular resistance index (PVRI) in c) MCT and d) hypoxia;

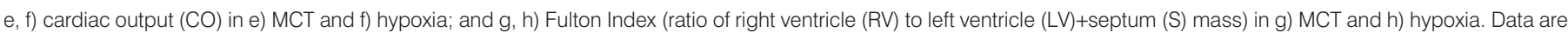
presented mean \pm SEM. ${ }^{*}: \mathrm{p}<0.05$ versus control; ${ }^{*}: \mathrm{p}<0.05$ treatment and control Ad+Fab-9B9 versus treatment and AdBMPR2+Fab-9B9. 

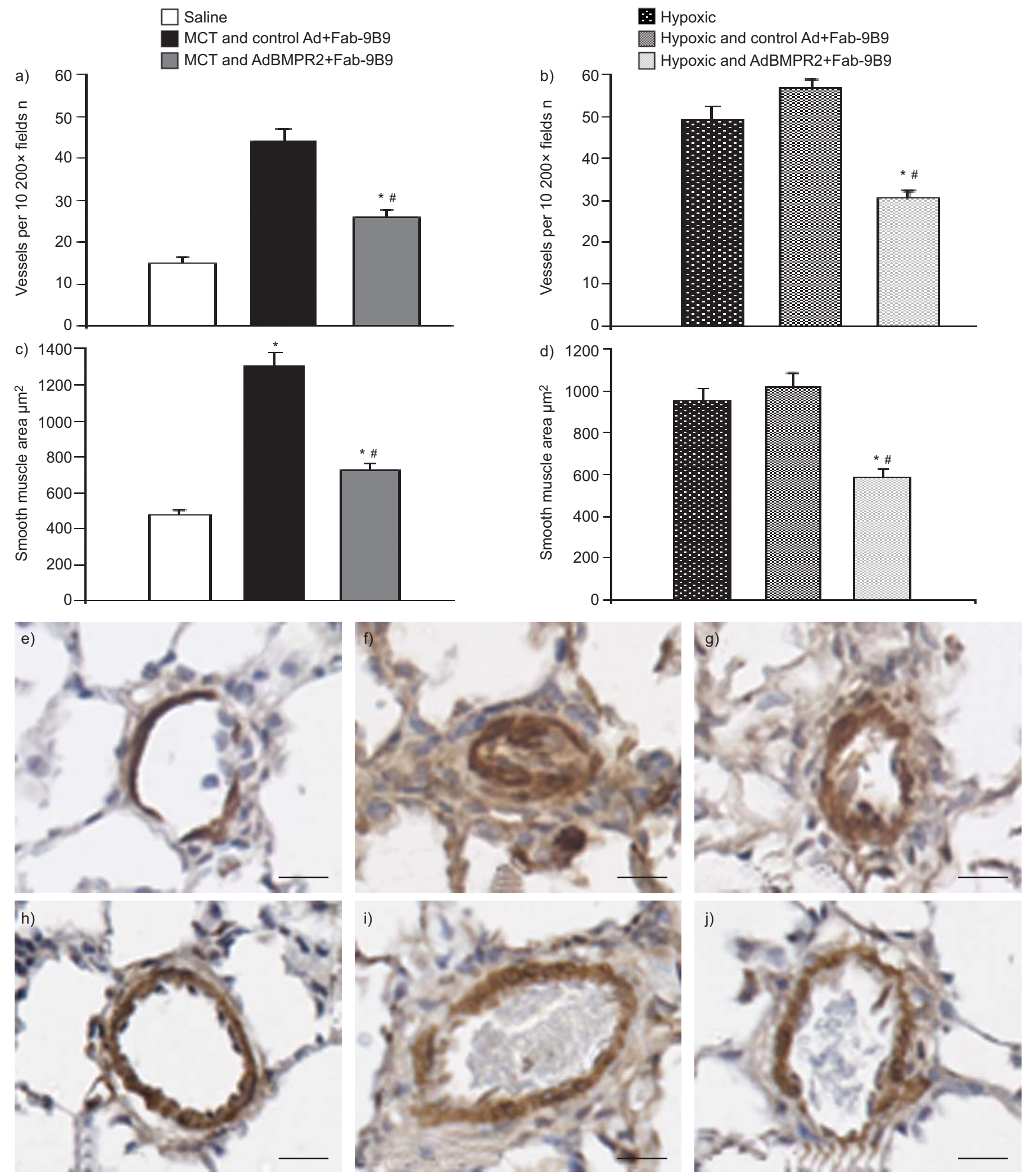

FIGURE 3. Number of small ( $\sim 50 \mu \mathrm{m})$ fully muscularised pulmonary arterioles per 10 random high-power fields $(200 \times)$ per animal, determined by smooth muscle $\alpha$ actin staining in a) monocrotaline (MCT) and b) hypoxia studies. Smooth muscle area of $1050-\mu \mathrm{m}$ vessels per animal in c) MCT and d) hypoxia studies. Data are presented as mean \pm SEM ( $n=4-5$ animals per group). *: $p<0.05$ versus control; * : $p<0.05$ treatment and control adenovirus (Ad) pre-incubated with anti-viral/anti-angiotensin-converting enzyme bispecific antibody conjugate (Fab-9B9) versus treatment and AdBMPR2+Fab+9B9. Representative high-power photomicrographs of small arteries from e) saline control, f) MCT and control Ad+Fab-9B9, g) MCT and AdBMPR2+Fab9B9, h) hypoxia, i) hypoxia and control Ad+Fab-9B9, and j) hypoxia and AdBMPR2+Fab9B9 animals. Sections were stained for smooth muscle $\alpha$-actin. Scale bars $=50 \mu \mathrm{m}$. 
Saline

MCT and control Ad+Fab-9B9

MCT and AdBMPR2+Fab-9B9
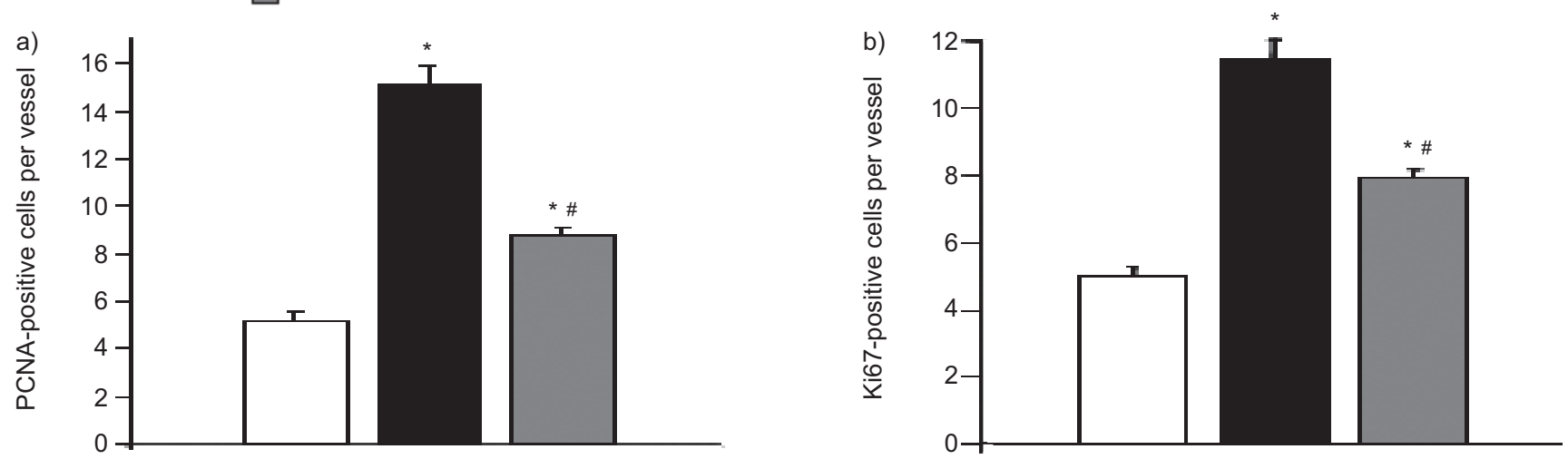

Hypoxic
Hypoxic and control Ad+Fab-9B9
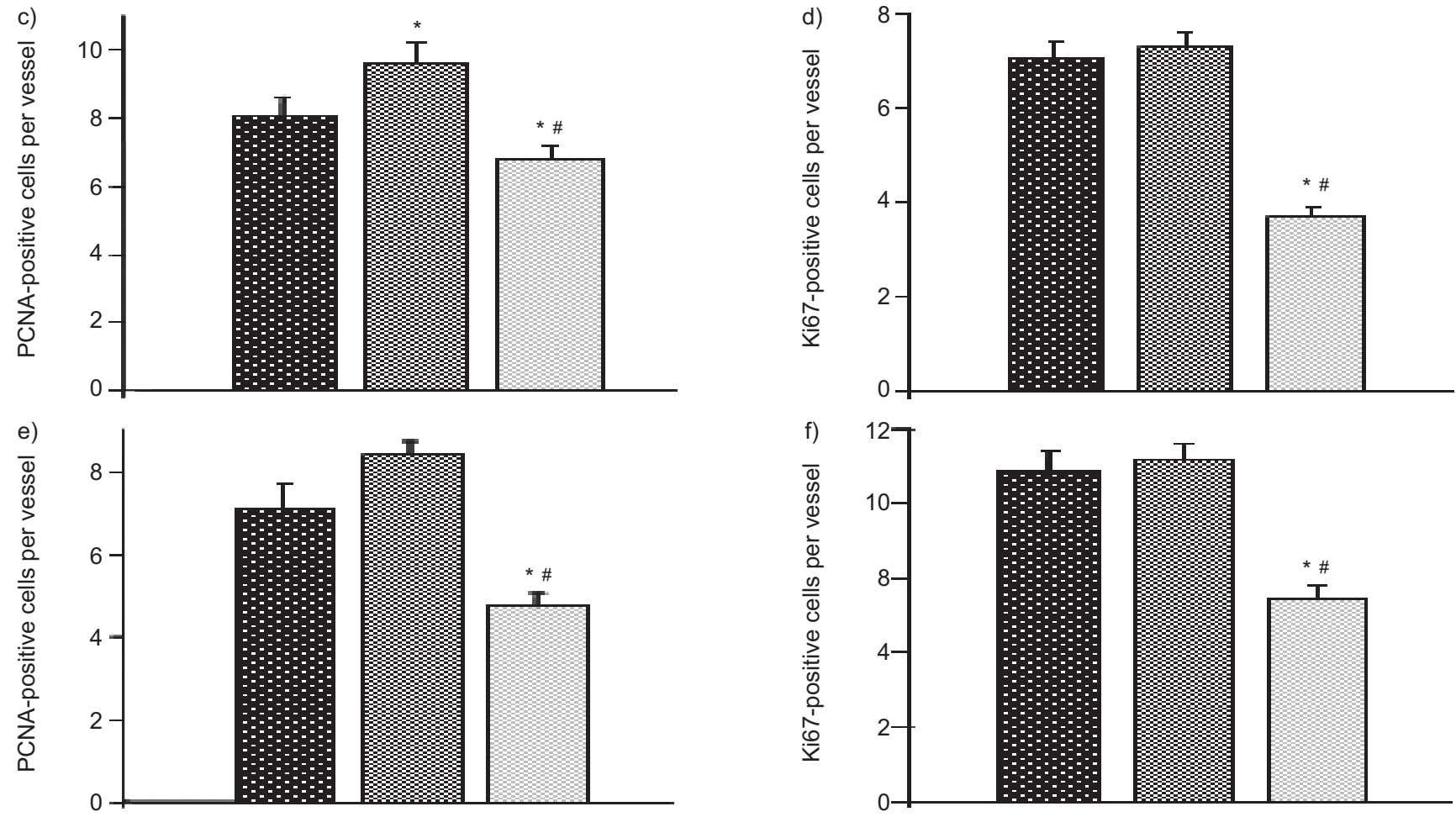

FIGURE 4. Quantification of $a, c, e)$ proliferating cell nuclear antigen (PCNA)- and b, d, f) Ki67-positive cell nuclei in a, b) monocrotaline (MCT)-induced endothelial lesions of small $(\sim 50 \mu \mathrm{m})$ vessels, c, d) endothelial cells and e, f) vascular smooth muscle cells of small $(\sim 50 \mu \mathrm{m})$ vessels in the hypoxia-treated groups. 10 vessels per animal were assessed. $n=4-5$ animals per group. Data are presented mean \pm SEM. ${ }^{*}: p<0.05$ versus control; ${ }^{*}: p<0.05$ treatment and control adenovirus (Ad): + Fab-9B9 versus treatment and AdBMPR2+Fab-9B9.

hypoxia and AdBMPR2+Fab-9B9 group, TGF- $\beta$ expression was $103.3 \pm 22.7 \%$ ). Similar results have been observed by others at the mRNA level [17].

Using immunoblot analysis, we were unable detect differences in TGF- $\beta$ receptor 1 or 2 expression in either model (data not shown). However, the analysis of endoglin expression showed a significant reduction after MCT (mean \pm SEM $100.0 \pm 26.7 \%$ versus
$55.9 \pm 20.1 \%$ of control in saline versus MCT and control Ad+Fab9B9, respectively; $\mathrm{p}<0.05$ ) (fig. 6a). AdBMPR2 treatment attenuated this response $(87.7 \pm 19.7 \% ; \mathrm{p}<0.05)$. In contrast, endoglin expression was significantly elevated in the hypoxia model $(100.0 \pm 43.9 \%$ versus $239.5 \pm 35.5 \%$ in saline versus hypoxia and control Ad+Fab-9B9, respectively; $\mathrm{p}<0.05$ ) (fig. 6b). Again, AdBMPR2 treatment attenuated the increase seen in the hypoxia model $(178.5 \pm 33.5 \% ; \mathrm{p}<0.05)$. 

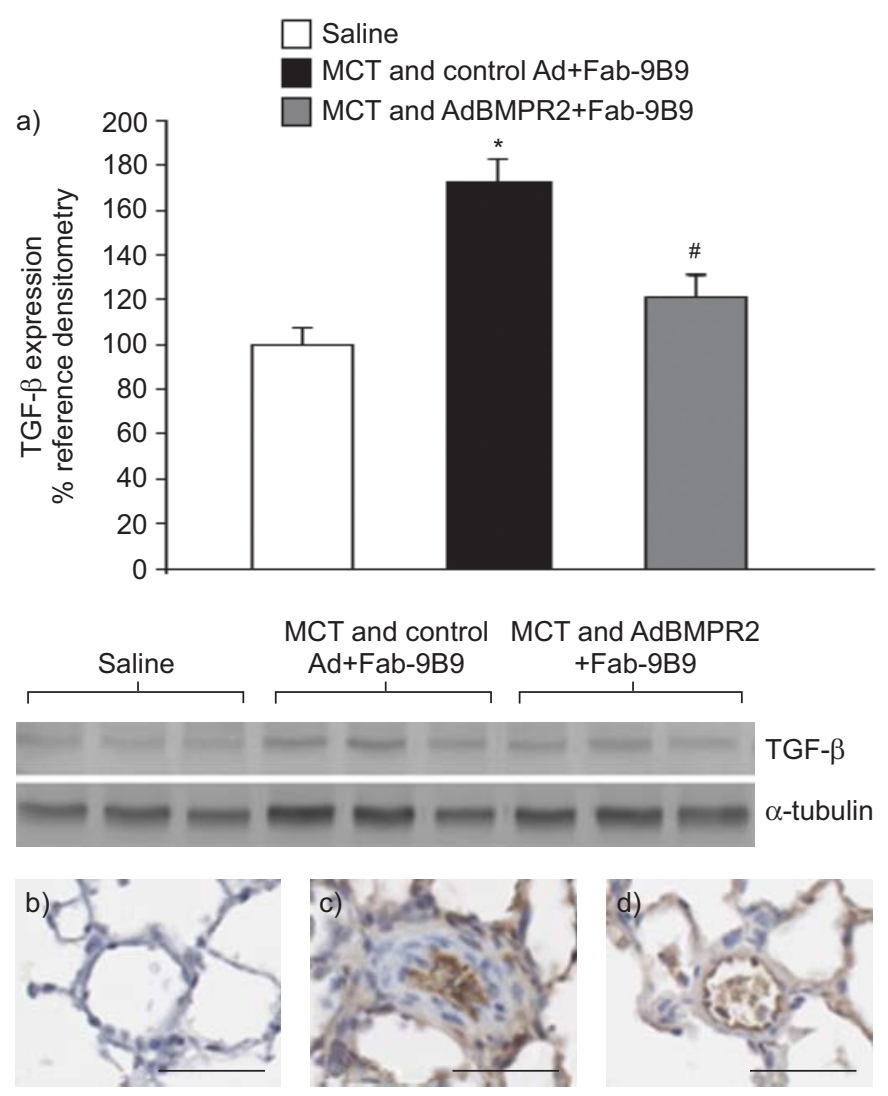

FIGURE 5. Quantification of transforming growth factor (TGF)- $\beta$ expression from immunoblots in saline, monocrotaline (MCT) and control adenovirus (Ad) preincubated with anti-viral/anti-angiotensin-converting enzyme bispecific antibody conjugate (Fab-9B9), and MCT and AdBMPR2+Fab-9B9-treated rats. Values are calculated as the ratio of chemiluminescence of the respective TGF- $\beta$ signal over the housekeeper protein ( $\alpha$-tubulin) and then expressed as $\%$ change in ratio from the saline group. Data are presented as mean \pm SEM. *: $p<0.05$ versus saline; \#: $\mathrm{p}<0.05$ for MCT and control Ad+Fab-9B9 versus MCT and AdBMPR2+Fab-9B9. Representative immunoblots of lung TGF- $\beta$ and $\alpha$-tubulin expression for $n=6$ animals in each treatment group are shown below the graph. Representative highpower photomicrographs of small arteries stained for TGF- $\beta$ in b) saline control, c) MCT and control Ad+Fab-9B9, and d) MCT and AdBMPR2+Fab-9B9 animals. Scale bars $=50 \mu \mathrm{m}$.

\section{Effect of TGF-ק1 on cellular morphology/EndMT in HPMVECs}

We next wished to investigate the biological effect of TGF- $\beta$ on HPMVECs and the impact of BMPR2 stimulation in this context. Under control conditions (without TGF- $\beta 1$ ), HPMVECs showed a cobblestone appearance and cell-cell adhesion was clearly observed (fig. 7a). HPMVECs exposed to TGF- $\beta 1\left(5 \mathrm{ng} \cdot \mathrm{mL}^{-1}\right)$ over a 20-day period demonstrates a decrease in cell-cell contacts and a change in cell morphology to elongated, spindle-like fibroblasts (fig. $7 \mathrm{~b}$ ). Time course studies demonstrated that a 20-day TGF- $\beta 1$ treatment regime was optimal in inducing EndMT in HPMVECs (data not shown). That is, TGF- $\beta 1$ treatment induced an upregulation of mesenchymal marker expression (e.g. fibronectin and S100A) with a concomitant downregulation of the endothelial marker VE-cadherin (fig. 7c-k). Minimal basal expression of fibronectin and S100A was detected in untreated HPMVECs. Following 20 days of treatment with TGF- $\beta 1$, HPMVEC fibronectin and S100A staining was stronger in the spindle-shaped, fibroblasttype cells. High basal expression of VE-cadherin was detected, which became significantly reduced in TGF- $\beta 1$-treated cells.

\section{Immunoblotting analysis of EndMT markers}

To quantify markers of EndMT, we used obtained total cell lysates of HPMVEC s treated for 20 days with TGF- $\beta 1\left(5 \mathrm{ng} \cdot \mathrm{mL}^{-1}\right.$ replenished every $48 \mathrm{~h}$ ) and performed immunoblot assays. TGF- $\beta 1$ treatment significantly increased mesenchymal marker expression; fibronectin expression increased 14-fold (fig. 8a) and vimentin almost doubled $(n=2$; data not shown), with a concomitant decrease in VE-cadherin expression of 30\% (fig. 8b), which was consistent with the immunofluorescence results. The proliferative response of HPMVECs treated with TGF- $\beta 1$ increased by $30 \%$ (fig. $8 \mathrm{c}$ ).

\section{Effect of TGF- $\beta 1$ on BMPR2 expression in HPMVECs}

Having confirmed the increase in TGF- $\beta$ and the reduction in BMPR2 in the rat models (and the reduced TGF- $\beta$ with BMPR2 upregulation), we next assessed the impact of TGF- $\beta 1$ on HPMVECs. Incubation of cells with TGF- $\beta 1$ resulted in a reduction in mean \pm SEM BMPR2 protein levels, being $65.8 \pm 10.9 \%$ that of untreated HPMVECs (fig. 8d).

\section{Reversal of TGF-ß1-induced EndMT by the BMPR2 ligands rhBMP-7 and rhBMP-2}

To determine the effect of upregulation of the BMP axis in EndMT, we repeated the TGF- $\beta 1$-induced EndMT studies in the presence of BMP-2 and BMP-7. The dose of BMP-2 and BMP-7 was $67 \%$ less than that used in a cardiac fibrosis cell culture model of TGF- $\beta$-induced EndMT [22]. Again, TGF- $\beta 1$-induced significant upregulation in fibronectin expression (160-200-fold change; fig. 9a and c) and decreased VE-cadherin expression (36-39\%; fig. 9b and d). Under the continuous influence of TGF$\beta 1$, the addition of rhBMP-2 (333 ng. $\mathrm{mL}^{-1}$ for $72 \mathrm{~h}$ ) and rhBMP-7 (325 ng $\cdot \mathrm{mL}^{-1}$ for $72 \mathrm{~h}$ ) substantially inhibited TGF- $\beta 1$-induced fibronectin production; fibronectin production was $33 \%$ and $51 \%$, respectively, compared with TGF- $\beta 1$ alone (fig. 9a and c). Vascular cell integrity appeared to be either fully or partially restored by BMP-2 and BMP-7, respectively, since both treatments significantly reversed the TGF- $\beta 1$ decline in VE-cadherin expression by $59 \%$ and $21 \%$, respectively (fig. $9 \mathrm{~b}$ and d). No difference in basal expression of either fibronectin or VEcadherin was detected when HPMVECs were incubated with BMP-2 or BMP-7 alone (data not shown).

\section{DISCUSSION}

The causal relationship between BMPR2 mutations and PAH is now accepted based on numerous human genetic studies and supportive evidence from transgenic mouse models [23, 24]. A logical extension of this discovery is that the BMPR2 pathway might be a novel target for therapeutic manipulation, although this strategy has received little attention to date. Our previous work established that BMPR2 gene delivery targeted to the lung endothelium via anti-ACE monoclonal antibody (mAb) could ameliorate hypoxia-induced pulmonary hypertension, in a preventive study design [14].

In the current study, we extend our previous findings in several ways. We now show that BMPR2 upregulation has a therapeutic impact in the setting of established PAH in two complementary animal models of PAH. These findings are entirely in accord with 

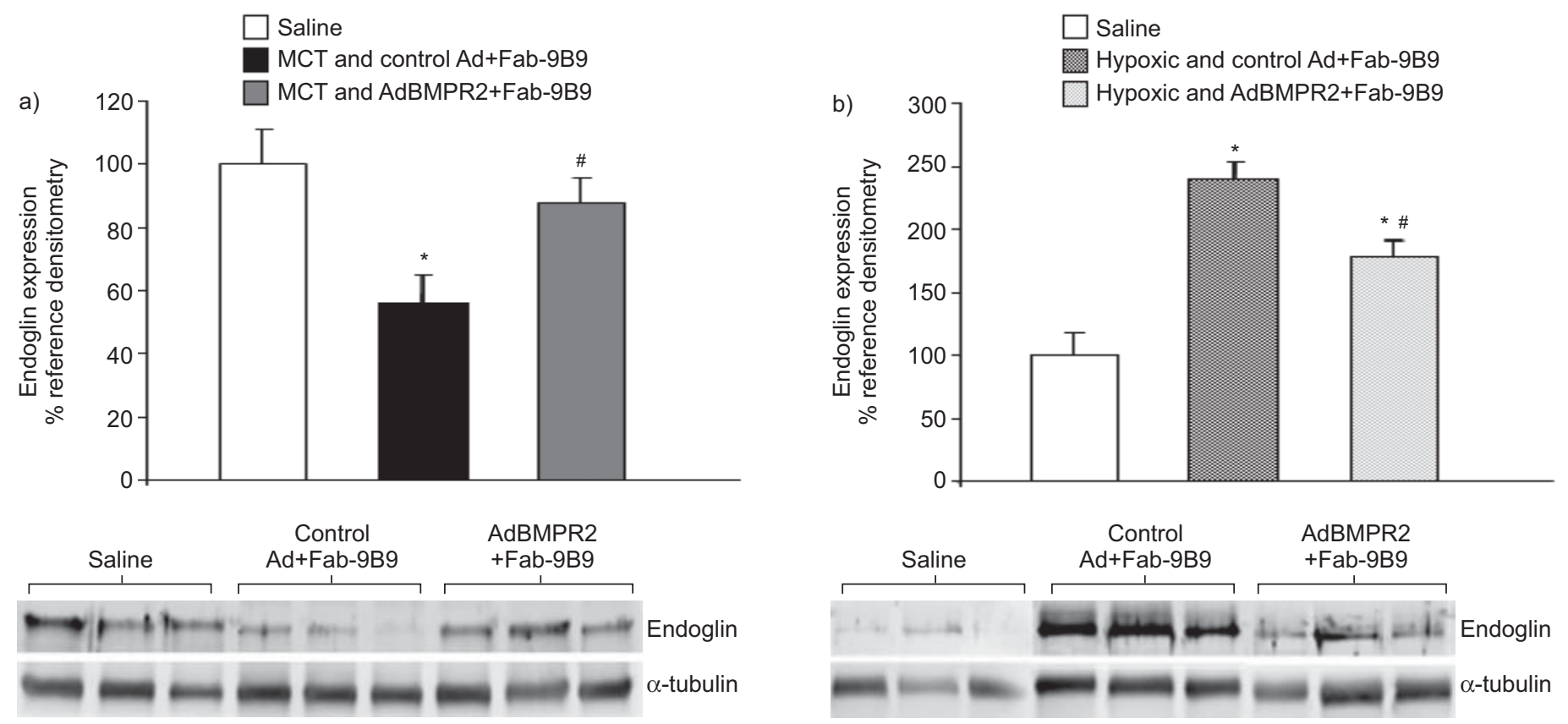

FIGURE 6. Quantification of endoglin expression by image analysis of immunoblots in a) monocrotaline (MCT)- and b) hypoxia-treated rats. Representative immunoblots of BMPR2 and $\alpha$-tubulin expression are shown below their respective graphs. Values are calculated as the ratio of chemiluminescence of the respective endoglin signal over the housekeeper protein ( $\alpha$-tubulin) and then expressed as $\%$ change in ratio from the saline group. Data are presented as mean \pm SEM. $n=6$ animals in each treatment group. *: $p<0.05$ versus saline; ${ }^{*}: p<0.05$ treatment and control adenovirus (Ad) pre-incubated with anti-viral/anti-angiotensin-converting enzyme bispecific antibody conjugate (Fab-9B9) versus treatment and AdBMPR2+Fab-9B9.

previous work showing that PAH in both the hypoxia and MCT model systems is associated with downregulation of BMPR2 $[12,13]$. Importantly, there is now ample evidence that BMPR2 is downregulated in the setting of human disease in many contexts beyond BMPR2 mutations, thus broadening the potential applicability of treatments targeted to this pathway [6, 25-27]. Although significant improvements have been made in PAH management in recent years based on the use of prostacyclin analogues, endothelin receptor antagonists and phosphodiesterase- 5 inhibitors, there are many patients who ultimately fail on these treatments and the search for new approaches is ongoing (for example, current clinical trials using imatinib). Taken together, our findings provide a rationale to consider the development of therapies based on BMPR2 modulation.

The mechanistic link between BMPR2 dysfunction and the development of pulmonary vascular disease remains unclear. Recent studies using the hypoxia and MCT models have demonstrated reduced BMPR2 levels and abnormal BMP/TGF signalling, while more recently, TGF- $\beta$ has been shown to be particularly upregulated in the MCT model [17, 28, 29]. Herein, we confirmed a reduction in pulmonary BMPR2 protein expression in both model systems and showed that this reduction was prevented by BMPR2 gene delivery. We showed a significant increase in TGF- $\beta$ in the MCT model, which was reversed with BMPR2 treatment. The increase in TGF- $\beta$ was not seen in the hypoxia model. The relative differences in the role of TGF- $\beta$ in these models have been noted by others [17]. LoNG et al. [17] found that TGF- $\beta$ was substantially increased in the MCT model and that using a small molecule to block one of the TGF- $\beta$ receptors (activin-like kinase 5) reduced PAH. In contrast, this blockade had no effect on hypoxia-induced PAH. In our study, correction of reduced BMPR2 expression showed benefits in both model systems.

A weakness of the present study is the uncertainty in regard to the precise cell signalling pathways that are involved in the physiological and remodelling effects we see with BMPR2 gene delivery. The demonstration of significant physiological outcomes provides a rationale for further interrogation of these mechanisms. In our previous work, we investigated whether $B M P R 2$ transduction acted in some way to protect endothelium from apoptosis, as it has been hypothesised that disease pathogenesis may begin with a phase of increased apoptosis leading to the emergence of apoptosis-resistant clones. Such a mechanism of early apoptosis remains unproven in the development of human PAH, although there is evidence for relative resistance to apoptosis in established disease [30]. Unexpectedly, we previously found in the rat hypoxia model and in human microvascular cell cultures that transduction with BMPR2 lead to increased apoptosis. Thus, we speculate that in established disease, it may be that BMPR2 transduction is affecting the endothelium via the downregulation of endothelium-derived pro-proliferative factors or having an impact on EndMT.

$\mathrm{BMP}$ signalling involves ligand-initiated heterodimerisation of cell-surface BMPR2 and BMPR1 (A or B), activation of the latter, then phosphorylation of a series of receptor-regulated Smad proteins (e.g. Smad1, Smad5 and Smad8) that, in turn, complex with the common partner Smad $(\operatorname{Smad} 4)$ and translocate into the nucleus to regulate target gene transcription [31]. In the context of PAH development, it has been proposed that TGF- $\beta$ cell signalling appears to primarily involve Smad2 and Smad3 signalling [32], although there is conflicting data in the literature 

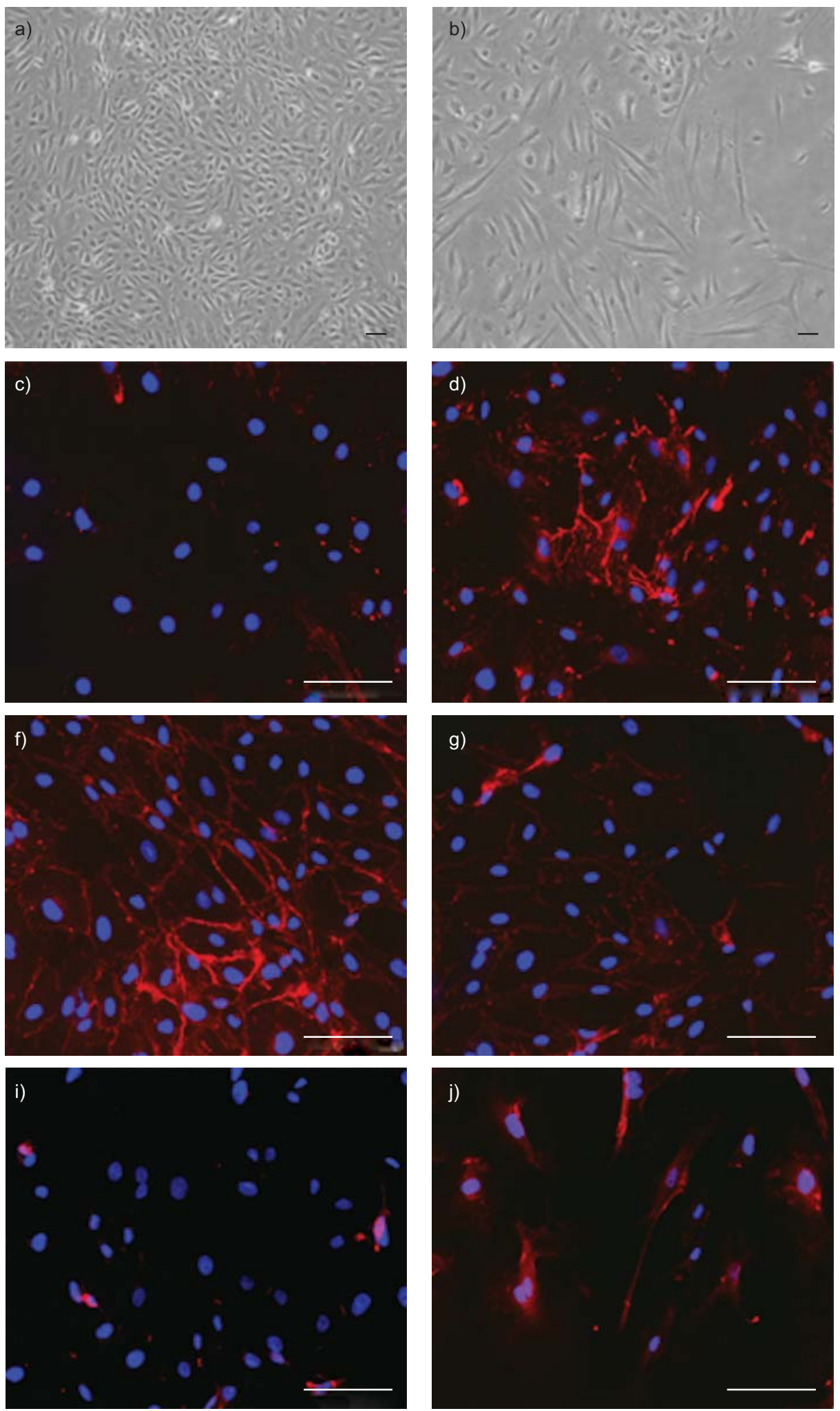
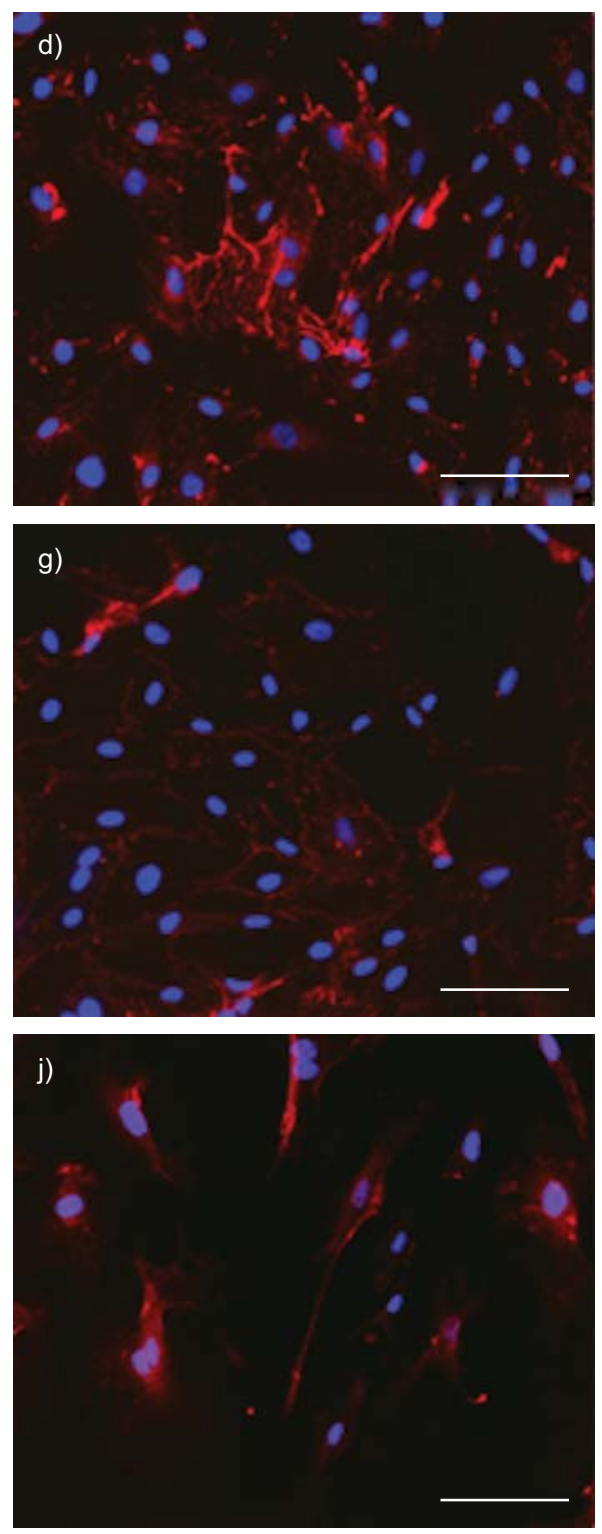
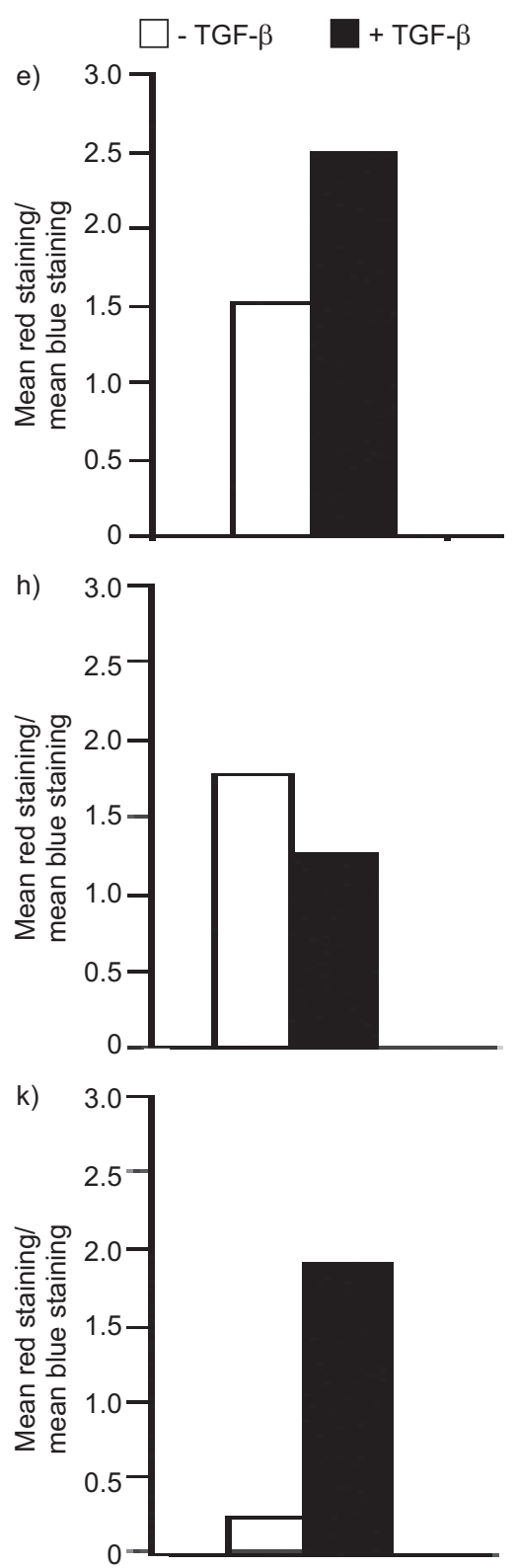

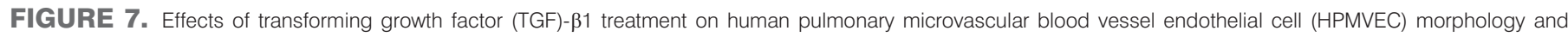

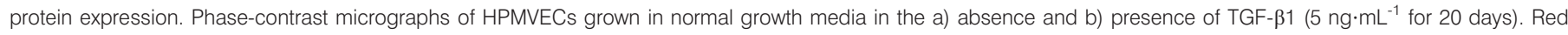

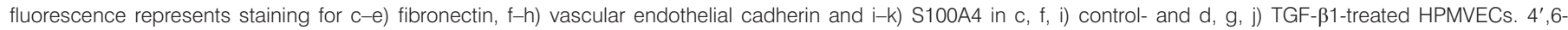

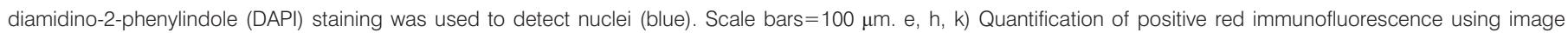
analysis software. The mean red fluorescence intensity was calculated for each photo and normalised by dividing this intensity by the mean blue intensity. 

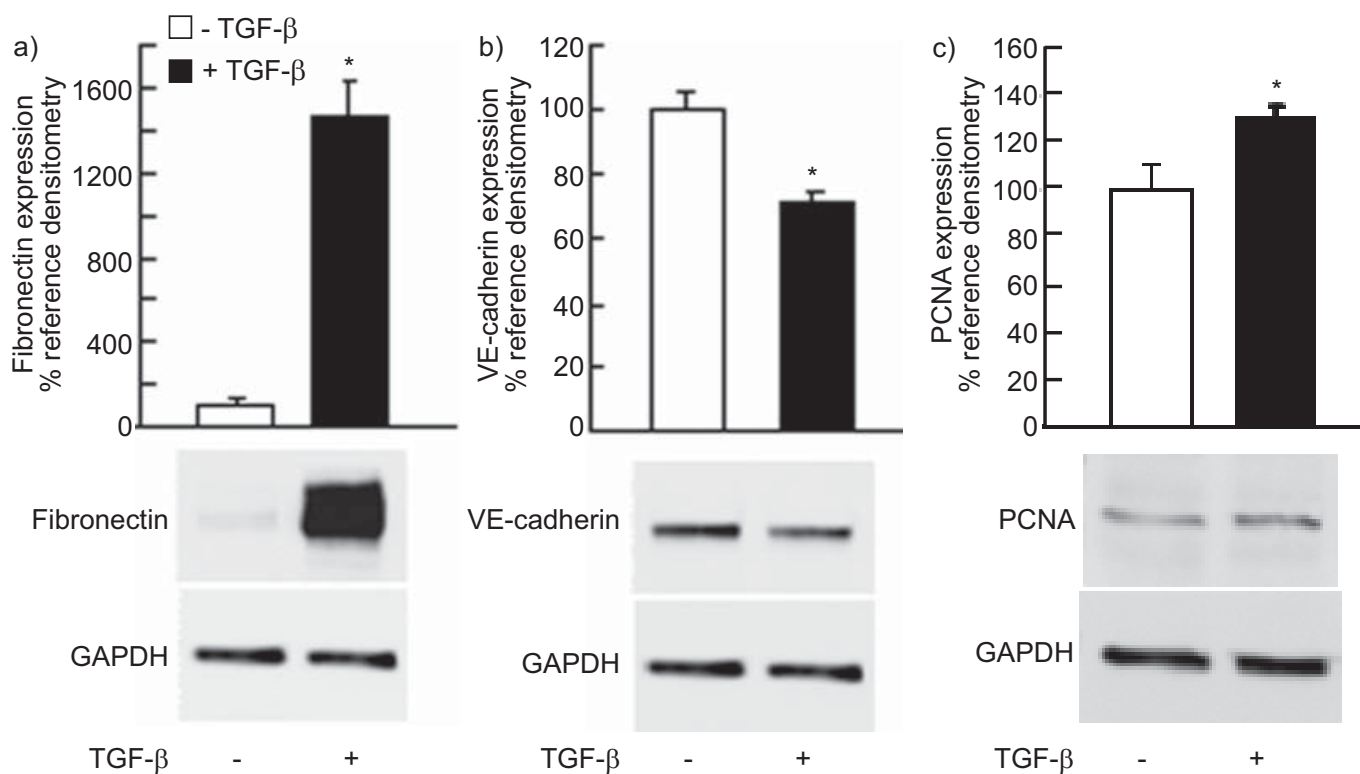

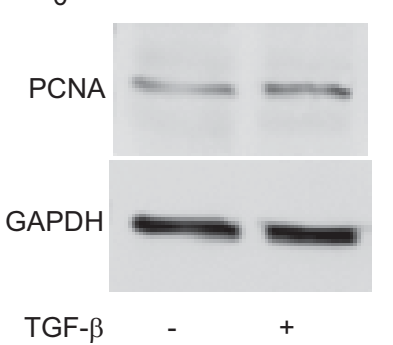

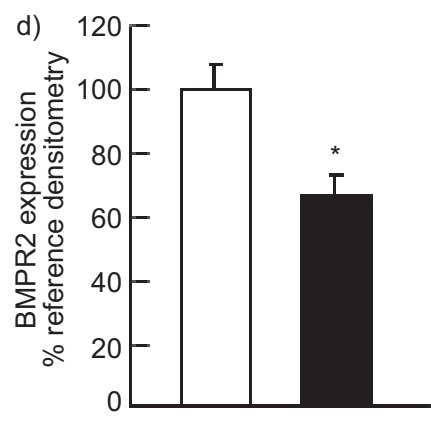

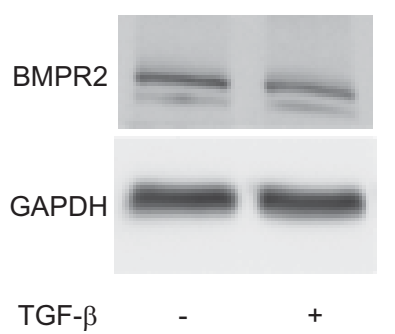

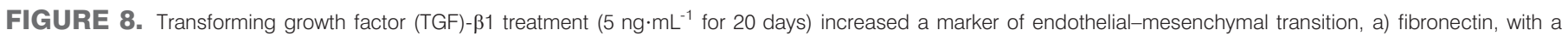

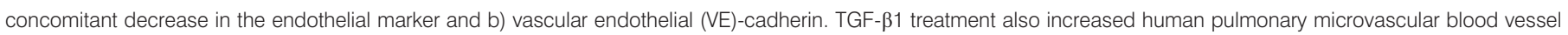

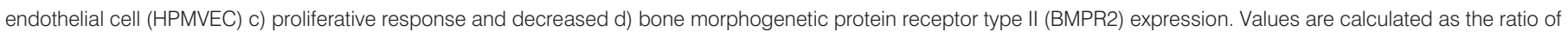

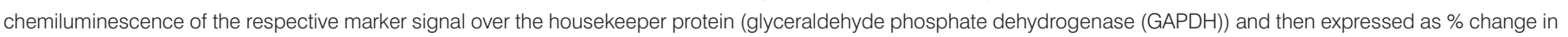

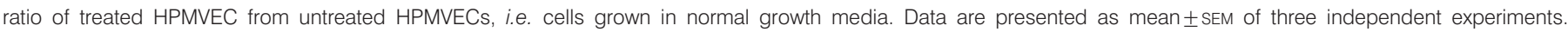
Immunoblots are from one representative experiment. PCNA: proliferating cell nuclear antigen. *: $p<0.05$ versus control (no TGF- $\beta 1$ ) by t-test.

on this issue, with ZAKRZEWICZ et al. [28] showing reduction of activity of this pathway in the MCT model, whereas LONG et al. [17] showed an increase. The reason for this apparent discrepancy is uncertain, but may be due to differences in the timing of the assays relative to disease onset. UPTON et al. [32] recently proposed a balance between TGF- $\beta-S m a d 2 / 3$ signalling and BMPR2-Smad1/5/8 signalling may be important in controlling cellular responses in the pulmonary vasculature. Unfortunately, technical limitations with the analysis of the formalin-fixed tissues derived from the rats used in the physiological studies prevented accurate characterisation of Smad or p38-MAPK mechanisms and this is the subject of ongoing studies. However, we did find robust changes in the levels of endoglin expression, with clear differences in the MCT and hypoxia models. Our finding of reduced endoglin in the MCT model is consistent with the mRNA findings reported by ZAKRZEWICZ et al. [28]. Endoglin acts as a co-receptor for TGF- $\beta$ signalling and has recently been shown to enhance TGF- $\beta$-induced phosphorylation of Smad1/ $5 / 8$ [33]. We showed that BMPR2 upregulation was associated with a restoration of endoglin expression in the MCT model. To our knowledge, endoglin levels have not previously been reported in the rat hypoxia model, although hypoxia has been shown to increase endoglin expression in human endothelial cells in vitro, and in models of myocardial and placental ischaemia [34]. Thus, the role of endoglin in the two rat PAH models appears to be quite different and the link between BMPR2 and endoglin expression requires further investigation.

The BMP/BMPR signal transduction system is critical for controlling cell differentiation and apoptosis. The former uses the Smad signalling pathway, while the latter works through activation of p38-MAPK. It is now also known that these receptors form pre-formed receptor complexes to which the ligand binds, leading to Smad signalling, or BMP ligand-initiated receptor complexes, which leads to activation of p38-MAPK [35]. Whether pre-formed or ligand-initiated complex formation occurs depends on the relative number of BMPR2 and BMPR1A molecules on the cell surface [36]. Furthermore, it has been suggested that when BMPR2 expression levels fall below a critical $10 \%$ of normal expression, aberrant signalling prevails [32]. This phenomenon has been reported by others in both the hypoxic and MCT models $[13,37]$, where BMPR2 expression has fallen, causing normal Smad1/5/8 signalling to be virtually abolished. In our study, we confirmed significant falls in BMPR2 in association with $\mathrm{PAH}$ development, although the magnitude of $\sim 25 \%$ was less than that previously reported. These differences might be due to issues of timing of analysis or differences in the techniques used. Here, we have analysed total expression in tissue sections, which could potentially underestimate the relative magnitude of reduction in endothelial cells, but analysis of BMPR2 expression at the cellular level needs more work. Ad vector BMPR2 delivery targeted to the lung endothelium in our present study restored overall BMPR2 levels and, thus, possibly a balance of wild-type receptor availability at the cell.

The success of gene delivery is likely to be dependent on the specific target cell transduced, especially when delivering the gene for a membrane-bound receptor. Expression of BMPR2 on smooth muscle cells is felt to be important and many studies have shown dysfunctional smooth muscle proliferation in the setting of BMPR2 mutations. Our approach of targeting the endothelium does not directly address this issue. However, in contrast to our work, in vivo transduction of pulmonary vascular smooth muscle via an aerosol route did not lead to any physiological improvements when tested in the MCT model [38], which perhaps supports an important role for endothelial expression in this 

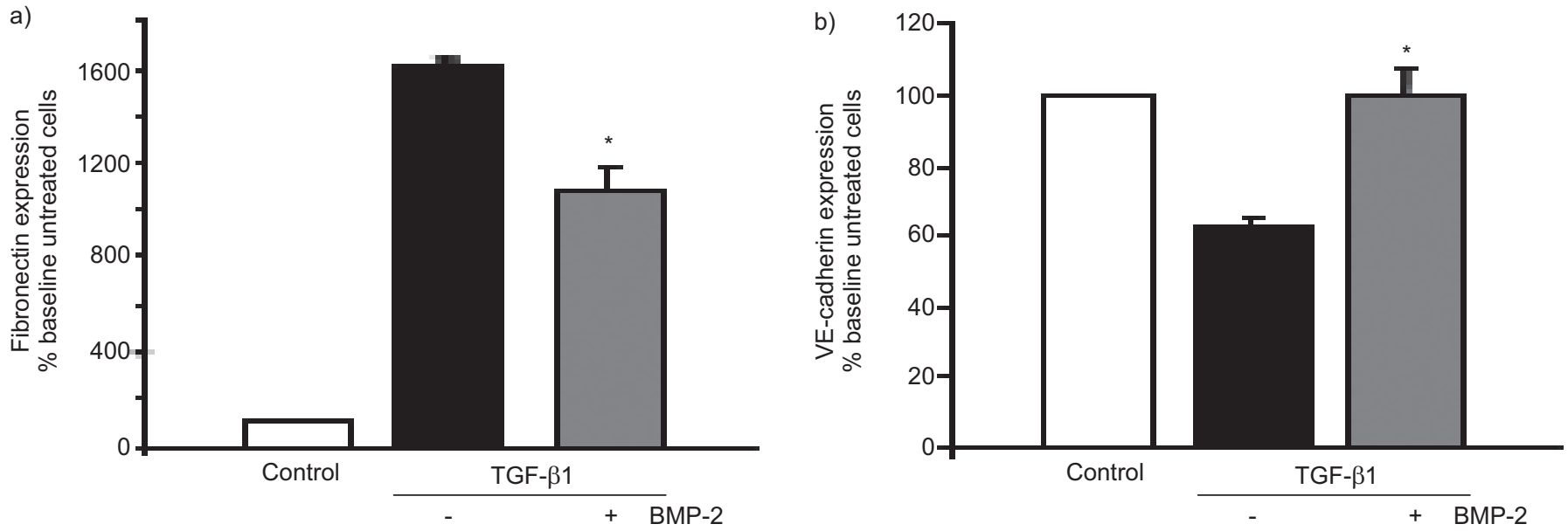

Fibronectin
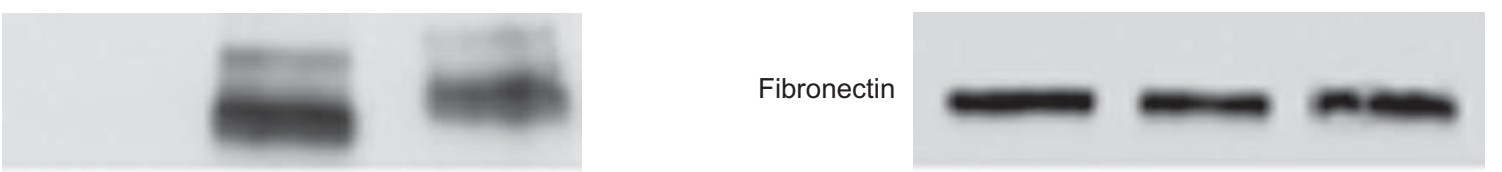

GAPDH

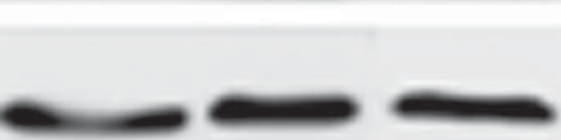

GAPDH
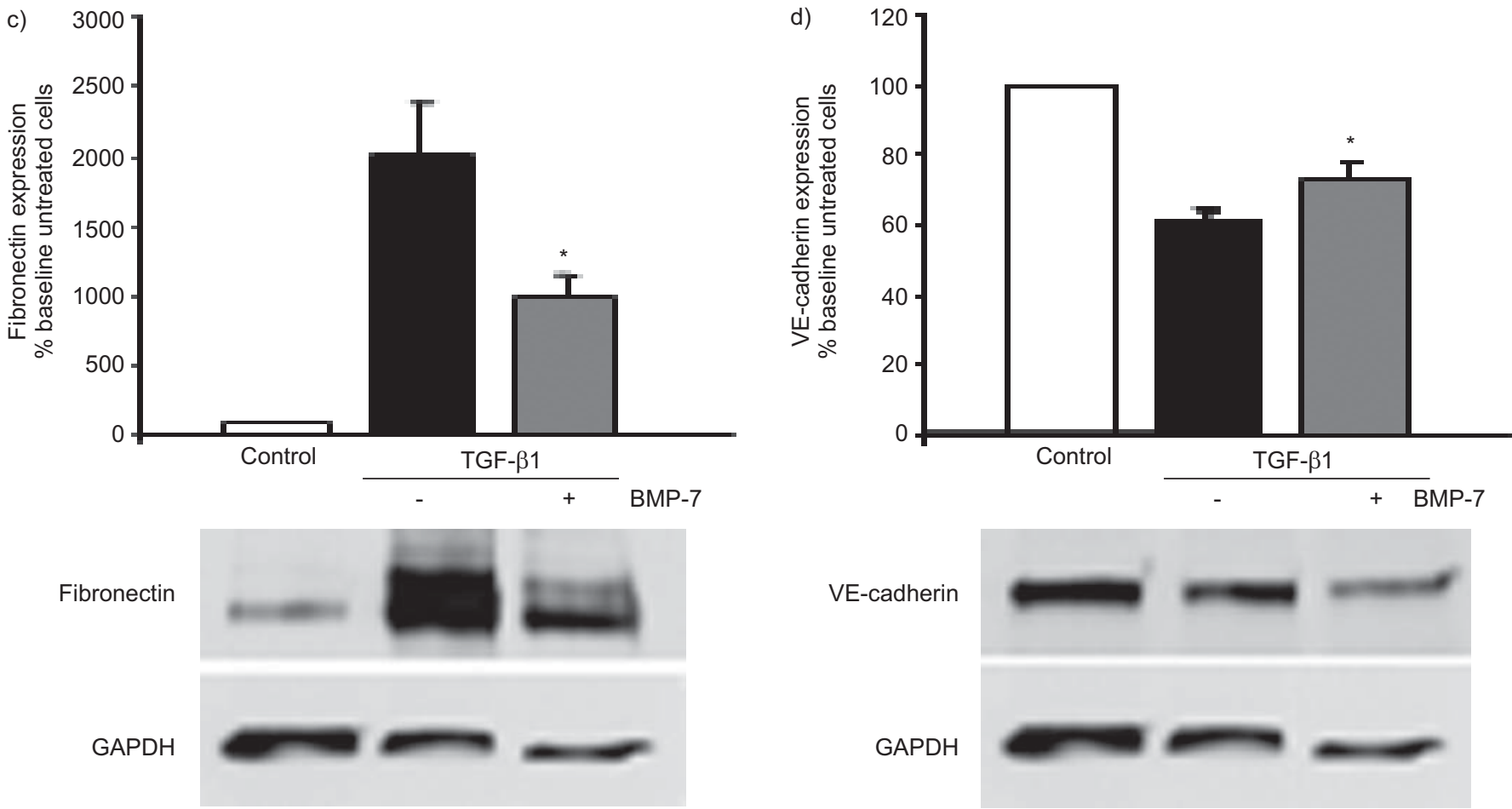

FIGURE 9. Immunoblot analysis of the effect of bone morphogenetic protein (BMP)-2 and BMP-7 on transforming growth factor (TGF)- $\beta 1$-induced endothelialmesenchymal transition in human pulmonary microvascular blood vessel endothelial cells (HPMVECs). Treatment with recombinant human (rh)BMP-2 a) significantly attenuated the increase in fibronectin expression induced by TGF- $\beta 1$, b) restored vascular endothelial (VE)-cadherin expression to baseline values. rhBMP-7 treatment, c) substantially reversed TGF- $\beta 1$ induced fibronectin production and d) partially restored endogenous VE-cadherin protein expression. Values are calculated as the ratio of chemiluminescence of the fibronectin or VE-cadherin signal over the housekeeper protein (glyceraldehyde phosphate dehydrogenase (GAPDH)) and then expressed as \% change in ratio of treated HPMVECs from untreated HPMVECs, i.e. cells grown in normal growth media. Data are presented as mean \pm SEM of three independent experiments. Immunoblots are from one representative experiment. *: $p<0.05$ versus TGF- $\beta 1$ treatment. 
setting. Our previous work using this gene delivery technique and reporter genes did not show significant cardiac expression, and we could not detect transgene expression in cardiac tissue by immunofluorescence in the current study. Thus, we believe the positive outcomes are due to the effect on pulmonary vessels rather than any direct cardiac effect. Much more work is required to determine the optimal approach if a gene delivery strategy is to achieve clinical utility.

Recently, TGF- $\beta$-induced EndMT has gained impetus as a mechanism for fibrotic lung diseases [39]. EndMT has also been investigated for its potential role in vascular disease. Those studies that have shown EndMT in response to TGF- $\beta 1$ have used animal primary endothelial cultures from larger blood vessels [40,41] or human dermal endothelial cells [42]. Based on dosing and time-course studies reported by others [22, 43], we chose a dosing regime of $5 \mathrm{ng} \cdot \mathrm{mL}^{-1}$ in normal growth media and an 18-21-day exposure period to test whether TGF- $\beta 1$ could induce EndMT in more relevant HPMVECs, and herein, report that following stimulation with TGF- $\beta 1$, HPMVECs demonstrated a change from their cobblestone morphology to spindleshaped, fibroblast-like morphology. We also observed a loss of endothelial marker expression (VE-cadherin) with a gain in expression of mesenchymal markers (fibronectin and S100A4). Of particular relevance to the current study, we also found that TGF- $\beta 1$ stimulation lead to a reduction of BMPR2 expression. Although we have evaluated our BMPR2 gene delivery vector in this setting, the studies were hampered by poor transduction efficiency of these cells (which do not express ACE in culture). Therefore, we added exogenous BMPs in an effort to restore the balance in BMPR2/TGF- $\beta$ signalling and have provided evidence for a protective role of BMPs in TGF- $\beta$-induced EndMT. Our results show that BMP-2 and BMP-7 lead to a reversal of EndMT even in the ongoing presence of TGF- $\beta 1$, and are consistent with a model of cardiac fibrosis where rhBMP-7 delivery inhibited EndMT and the progression of cardiac fibrosis [22]. The dose of BMPs we used to show an effect was one-third of that considered optimal in the cardiac study, but we did not see significant effects at doses lower than this. At this time, the role of EndMT in PAH remains a novel hypothesis that is generating significant interest in the field, as noted in recent reviews [44-46]. Transdifferentiation of pulmonary arteriolar endothelial cells into smooth muscle-like cells has been shown in hypoxia-induced pulmonary vascular remodelling [41]. Support for the EndMT concept has been found in other contexts, including myocardial fibrosis, atherosclerosis, wound healing and vascular development [44]. However, definitive proof of a role for EndMT in human PAH has not yet been established.

A major hurdle for the development of BMPR2 gene therapy is of course the translation of our approach to a strategy that is feasible in the human clinical setting. Gene therapy approaches for human disease generally have struggled to have a significant clinical impact. Much of this difficulty relates to the limitations of the vector technology used for gene delivery. In the current study, we have used our previously established approach to target lung endothelium via anti-ACE $\mathrm{mAb}$, which we have shown improves pulmonary vascular gene delivery [20,21]. Our approach achieved useful outcomes in contrast to aerosol delivery of vector, which did not reduce PAH in the MCT model [38]. Importantly, it may be critical that our strategy achieved endothelial cell transduction (the predominant site of
BMPR2 expression in the lung) whereas the aerosol route chosen by MCMURTRY et al. [38] was aimed at vascular smooth muscle. Nevertheless, our current work remains, in essence, at the proofof-principle stage. The duration of enhanced BMPR2 expression needed to achieve a therapeutic outcome in the context of $B M P R 2$ mutations is not clear. BMPR2 mutations have limited penetrance for causing clinical disease $(<20 \%$ of mutation carriers develop disease) and it is generally accepted that some form of "second hit" is necessary for this to occur. Perhaps transient BMPR2 overexpression, even for a short number of weeks, could interrupt the pathological cascade. The firstgeneration Ad vectors that we have used here can only achieve short-term expression (typically a short number of weeks in immunocompetent animals) and are not suitable for re-administration due to the development of neutralising antibodies. However, the fact that significant physiological outcomes can be achieved with the current vector technology bodes well for further improvements as vector technology evolves. Evolution in vector technology is already well underway with the development of genetically retargeted vectors, recombinant targeting adapters, and modifications of virus to reduce hepatic uptake and circumvent pre-existing immunity [47, 48]. Longer term transgene expression may be achieved with helper-dependant Ad vectors, to which the targeting technologies can be applied [49]. There is also growing interest in the use of cells as gene delivery vehicles and cells transduced with endothelial nitric oxide synthase are already in a phase I clinical trial [50]. Alternatively, more conventional pharmaceuticals might be directed to this pathway. For example, some BMPR2 mutations lead to production of potentially functional protein that fails to reach the cell membrane due to abnormal folding. Improved trafficking, with pharmacological chaperones, such as thapsigargin or glycerol, which have efficacy for redirecting BMPR2 mutants, may help restore BMPR2 signalling in a subset of patients [51]. The rather disappointing survival figures from recent national registry studies clearly indicate the need for ongoing development of new approaches to treatment that may complement existing strategies.

In summary, the current study provides evidence that increasing BMPR2 expression using a gene delivery approach improves physiological outcomes in two common rat models. Much more development is needed to determine whether such an approach might have relevance in the human disease.

\section{SUPPORT STATEMENT}

This study was supported by a National Health and Medical Research Council Project Grant and Practioner Fellowship, and a National Heart Foundation of Australia Grant-in-Aid.

\section{STATEMENT OF INTEREST}

Statements of interest for S.M. Danilov and the study itself can be found at www.erj.ersjournals.com/site/misc/statements.xhtml

\section{REFERENCES}

1 Farber HW, Loscalzo J. Pulmonary arterial hypertension. N Engl J Med 2004; 351: 1655-1665.

2 Badesch DB, Champion HC, Sanchez MA, et al. Diagnosis and assessment of pulmonary arterial hypertension. J Am Coll Cardiol 2009; 54: Suppl. 1, S55-S66. 
3 Deng Z, Morse JH, Slager SL, et al. Familial primary pulmonary hypertension (gene PPH1) is caused by mutations in the bone morphogenetic protein receptor-II gene. Am J Hum Genet 2000; 67: 737-744.

4 Lane KB, Machado RD, Pauciulo MW, et al. Heterozygous germline mutations in BMPR2, encoding a TGF- $\beta$ receptor, cause familial primary pulmonary hypertension. The International PPH Consortium. Nat Genet 2000; 26: 81-84.

5 Machado RD, Eickelberg O, Elliott CG, et al. Genetics and genomics of pulmonary arterial hypertension. J Am Coll Cardiol 2009; 54: Suppl. 1, S32-S42.

6 Atkinson C, Stewart S, Upton PD, et al. Primary pulmonary hypertension is associated with reduced pulmonary vascular expression of type II bone morphogenetic protein receptor. Circulation 2002; 105: 1672-1678.

7 McLaughlin VV, Sitbon O, Badesch DB, et al. Survival with firstline bosentan in patients with primary pulmonary hypertension. Eur Respir J 2005; 25: 244-249.

8 Humbert M, Sitbon O, Chaouat A, et al. Survival in patients with idiopathic, familial, and anorexigen-associated pulmonary arterial hypertension in the modern management era. Circulation 2010; 122: 156-163.

9 Benza RL, Miller DP, Gomberg-Maitland M, et al. Predicting survival in pulmonary arterial hypertension: insights from the Registry to Evaluate Early and Long-Term Pulmonary Arterial Hypertension Disease Management (REVEAL). Circulation 2010; 122: 164-172.

10 McLaughlin VV, Suissa S. Prognosis of pulmonary arterial hypertension: the power of clinical registries of rare diseases. Circulation 2010; 122: 106-108.

11 Stenmark KR, Meyrick B, Galie N, et al. Animal models of pulmonary arterial hypertension: the hope for etiological discovery and pharmacological cure. Am J Physiol Lung Cell Mol Physiol 2009; 297: L1013-L1032.

12 Takahashi H, Goto N, Kojima Y, et al. Downregulation of type II bone morphogenetic protein receptor in hypoxic pulmonary hypertension. Am J Physiol Lung Cell Mol Physiol 2006; 290: L450L458.

13 Morty RE, Nejman B, Kwapiszewska G, et al. Dysregulated bone morphogenetic protein signaling in monocrotaline-induced pulmonary arterial hypertension. Arterioscl Thromb Vasc Biol 2007; 27: 1072-1078.

14 Reynolds AM, Xia W, Holmes MD, et al. Bone morphogenetic protein type 2 receptor gene therapy attenuates hypoxic pulmonary hypertension. Am J Physiol Lung Cell Mol Physiol 2007; 292: L1182-L1192.

15 Miyazono K, Maeda S, Imamura T. BMP receptor signaling: transcriptional targets, regulation of signals, and signaling crosstalk. Cytokine Growth Factor Rev 2005; 16: 251-263.

16 Stenmark KR, Fagan KA, Frid MG. Hypoxia-induced pulmonary vascular remodeling: cellular and molecular mechanisms. Circ Res 2006; 99: 675-691.

17 Long L, Crosby A, Yang X, et al. Altered bone morphogenetic protein and transforming growth factor- $\beta$ signaling in rat models of pulmonary hypertension: potential for activin receptor-like kinase- 5 inhibition in prevention and progression of disease. Circulation 2009; 119: 566-576.

18 Danilov SM, Gavrilyuk VD, Franke FE, et al. Lung uptake of antibodies to endothelial antigens: key determinants of vascular immunotargeting. Am J Physiol Lung Cell Mol Physiol 2001; 280: L1335-L1347.

19 Metzger R, Franke FE, Bohle RM, et al. Heterogeneous distribution of angiotensin I-converting enzyme (CD143) in the human and rat vascular systems: vessel, organ and species specificity. Microvascular Res 2011; 81: 206-215.

20 Reynolds PN, Zinn KR, Gavrilyuk VD, et al. A targetable, injectable adenoviral vector for selective gene delivery to pulmonary endothelium in vivo. Mol Ther 2000; 2: 562-578.
21 Reynolds PN, Nicklin SA, Kaliberova L, et al. Combined transductional and transcriptional targeting improves the specificity of transgene expression in vivo. Nat Biotechnol 2001; 19: 838-842.

22 Zeisberg EM, Tarnavski O, Zeisberg M, et al. Endothelial-tomesenchymal transition contributes to cardiac fibrosis. Nat Med 2007; 13: 952-961.

23 West J, Fagan K, Steudel W, et al. Pulmonary hypertension in transgenic mice expressing a dominant-negative BMPRII gene in smooth muscle. Circ Res 2004; 94: 1109-1114.

24 West J, Harral J, Lane K, et al. Mice expressing BMPR2R899X transgene in smooth muscle develop pulmonary vascular lesions. Am J Physiol Lung Cell Mol Physiol 2008; 295: L744-L755.

25 Morrell NW, Yang X, Upton PD, et al. Altered growth responses of pulmonary artery smooth muscle cells from patients with primary pulmonary hypertension to transforming growth factor- $\beta 1$ and bone morphogenetic proteins. Circulation 2001; 104: 790-795.

26 Yeager ME, Halley GR, Golpon HA, et al. Microsatellite instability of endothelial cell growth and apoptosis genes within plexiform lesions in primary pulmonary hypertension. Circ Res 2001; 88: 2e-11e.

27 Thomas M, Docx C, Holmes AM, et al. Activin-like kinase 5 (ALK5) mediates abnormal proliferation of vascular smooth muscle cells from patients with familial pulmonary arterial hypertension and is involved in the progression of experimental pulmonary arterial hypertension induced by monocrotaline. Am J Pathol 2009; 174: 380-389.

28 Zakrzewicz A, Kouri FM, Nejman B, et al. The transforming growth factor $\beta / \operatorname{Smad} 2,3$ signalling axis is impaired in experimental pulmonary hypertension. Eur Respir J 2007; 29: 1094-1104.

29 Burke DL, Frid MG, Kunrath CL, et al. Sustained hypoxia promotes the development of a pulmonary artery-specific chronic inflammatory microenvironment. Am J Physiol Lung Cell Mol Physiol 2009; 297: L238-L250.

30 Masri FA, Xu W, Comhair SA, et al. Hyperproliferative apoptosisresistant endothelial cells in idiopathic pulmonary arterial hypertension. Am J Physiol Lung Cell Mol Physiol 2007; 293: L548-L554.

31 Wrana JL, Attisano L. The Smad pathway. Cytokine Growth Factor Rev 2000; 11: 5-13.

32 Upton PD, Morrell NW. TGF- $\beta$ and BMPR-II pharmacology implications for pulmonary vascular diseases. Curr Opin Pharmacol 2009; 9: 274-280.

33 Lee NY, Ray B, How T, et al. Endoglin promotes transforming growth factor $\beta$-mediated Smad 1/5/8 signaling and inhibits endothelial cell migration through its association with GIPC. J Biol Chem 2008; 283: 32527-32533.

34 Tian F, Zhou AX, Smits AM, et al. Endothelial cells are activated during hypoxia via endoglin/ALK-1/SMAD1/5 signaling in vivo and in vitro. Biochem Biophys Res Commun 2010; 392: 283-288.

35 Hassel S, Schmitt S, Hartung A, et al. Initiation of Smad-dependent and Smad-independent signaling via distinct BMP-receptor complexes. J Bone Joint Surg 2003; 85: 44-51.

36 Nohe A, Keating E, Underhill TM, et al. Effect of the distribution and clustering of the type I A BMP receptor (ALK3) with the type II BMP receptor on the activation of signalling pathways. J Cell Sci 2003; 116: 3277-3284.

37 Takahashi K, Kogaki S, Matsushita T, et al. Hypoxia induces alteration of bone morphogenetic protein receptor signaling in pulmonary artery endothelial cell. Paediatric Res 2007; 61: 392-397.

38 McMurtry MS, Moudgil R, Hashimoto K, et al. Overexpression of human bone morphogenetic protein receptor 2 does not ameliorate monocrotaline pulmonary arterial hypertension. Am J Physiol Lung Cell Mol Physiol 2007; 292: L872-L878.

39 Willis BC, Borok Z. TGF- $\beta$-induced EMT: mechanisms and implications for fibrotic lung disease. Am J Physiol Lung Cell Mol Physiol 2007; 293: L525-L534.

40 Frid MG, Kale VA, Stenmark KR. Mature vascular endothelium can give rise to smooth muscle cells via endothelial-mesenchymal transdifferentiation: in vitro analysis. Circ Res 2002; 90: 1189-1196. 
41 Zhu P, Huang L, Ge X, et al. Transdifferentiation of pulmonary arteriolar endothelial cells into smooth muscle-like cells regulated by myocardin involved in hypoxia-induced pulmonary vascular remodelling. Int J Exp Path 2006; 87: 463-474.

42 Kitao A, Sato Y, Sawada-Kitamura S, et al. Endothelial to mesenchymal transition via transforming growth factor-beta1/Smad activation is associated with portal venous stenosis in idiopathic portal hypertension. Am J Pathol 2009; 175: 616-626.

43 Arciniegas $\mathrm{E}$, Sutton $\mathrm{AB}$, Allen $\mathrm{TD}$, et al. Transforming growth factor beta 1 promotes the differentiation of endothelial cells into smooth muscle-like cells in vitro. J Cell Sci 1992; 103: 521-529.

44 Arciniegas E, Frid MG, Douglas IS, et al. Perspectives on endothelial-to-mesenchymal transition: potential contribution to vascular remodeling in chronic pulmonary hypertension. Am J Physiol Lung Cell Mol Physiol 2007; 293: L1-L8.

45 Sakao S, Tatsumi K, Voelkel NF. Reversible or irreversible remodeling in pulmonary arterial hypertension. Am J Respir Cell Mol Biol 2010; 43: 629-634.
46 Sakao S, Tatsumi K, Voelkel NF. Endothelial cells and pulmonary arterial hypertension: apoptosis, proliferation, interaction and transdifferentiation. Respir Res 2009; 10: 95.

47 Izumi M, Kawakami Y, Glasgow JN, et al. In vivo analysis of a genetically modified adenoviral vector targeted to human CD40 using a novel transient transgenic model. J Gene Med 2005; 7: 1517-1525.

48 Roberts DM, Nanda A, Havenga MJ, et al. Hexon-chimaeric adenovirus serotype 5 vectors circumvent pre-existing anti-vector immunity. Nature 2006; 441: 239-243.

49 Brunetti-Pierri N, Ng P. Progress and prospects: gene therapy for genetic diseases with helper-dependent adenoviral vectors. Gene Ther 2008; 15: 553-560.

50 Jurasz P, Courtman D, Babaie S, et al. Role of apoptosis in pulmonary hypertension: from experimental models to clinical trials. Pharmacol Ther 2010; 126: 1-8.

51 Sobolewski A, Rudarakanchana N, Upton PD, et al. Failure of bone morphogenetic protein receptor trafficking in pulmonary arterial hypertension: potential for rescue. Hum Mol Genet 2008; 17: 3180-3190. 